\title{
Proton auroras during the transitional stage of substorm onset
}

\author{
Jun Liang ${ }^{1 *} \mathbb{C}$, Eric Donovan ${ }^{1}$, Deborah Gillies ${ }^{1}$, Emma Spanswick $^{1}$ and Martin Connors ${ }^{2}$
}

\begin{abstract}
Optical auroral measurements repeatedly reveal the existence of a transitional stage between a quiescent preexisting arc and its significant auroral expansion in a substorm onset. Such a transitional stage of substorm onset (TSSO) is characterized by a gradual intensification and the emergence of auroral beads, along the preexisting arc. However, existing studies on TSSO are limited to electron auroras which are dominant in optical luminosity. In this study, we collect 12 substorm events to investigate the proton auroral features during the late growth phase and the TSSO. Our major results include: (1) we confirm the previous notion that the onset electron auroral arc is usually located at the poleward "shoulder" of the main proton auroral band. (2) While the electron auroral arc typically intensifies by a few times or even an order of magnitude during the TSSO, the concurrent proton aurora at the same location as the electron auroral arc shows much less noticeable variations. The proton auroral variations averaged over the arc band, as well as that integrated over the entire latitudinal range, are mostly within 10\% of their mean late-growth-phase levels during the TSSO. Substantial intensifications of proton auroras occur after the poleward expansion of electron auroras. Even considering the spatial spreading of proton auroras, we estimate that the variation of ion precipitation fluxes on top of the ionosphere would be typically $<30 \%$ during the TSSO. The above observations impose implications and quantitative constraints on the possible mechanisms of TSSO and substorm onset. We assert that there is no significant ion energization or large-scale magnetic field reconfiguration during the TSSO. Instead, it is likely that the underlying mechanism of the TSSO might be certain kind of ky-dominated instability wave mode. The instability wavelength is comparable to the ion gyroradius, so that the ions are demagnetized, suppressing ion flux variations with the instability. Enhancing upward electric fields in the auroral acceleration region during the TSSO may also play a partial role in weakening the ion precipitation flux variation.
\end{abstract}

Keywords: Auroral substorm, Transition stage of substorm onset, Proton aurora, Electron aurora, Preexisting auroral arc, Nightside transition region

\section{Introduction}

Akasofu (1964) for the first time gave a morphological definition of an auroral substorm process. Three phases occur in a typical substorm, namely the growth phase, the expansion phase and the recovery phase. The growth phase is characterized by a preexisting arc that slowly migrates equatorward, indicating a gradually stretching magnetotail configuration. The expansion phase is characterized by violent brightening and significant poleward

\footnotetext{
*Correspondence: liangj@ucalgary.ca

${ }^{1}$ Department of Physics and Astronomy, University of Calgary, Calgary, Canada

Full list of author information is available at the end of the article
}

expansion of the auroras, signifying an explosive energy release accompanying a magnetic dipolarization in the tail. In a recovery phase, the magnetosphere slowly recovers to the presubstorm state over hours. The start of the expansion phase is termed as "substorm expansion phase onset" or "substorm onset". These classical depictions of substorm phases have lasted for decades.

In Akasofu's original categorization, the auroral morphology was grouped in 5-min resolution. Since then, significant advancements in camera sensitivity, coverage, and in particular the time resolution thanks to the extensive deployment of ground-based all-sky-imagers (ASIs), have unveiled many more details of the substorm auroral evolution. An intermediate yet important stage of 
substorm onset has been unveiled from a series of studies (e.g., Donovan et al. 2006; Liang et al. 2008, 2016; Sakaguchi et al. 2009; Rae et al. 2010; Liu et al. 2012; Chang and Cheng 2015; Kalmoni et al. 2015, 2017; Nishimura et al. 2016), and gradually becomes established in the substorm research community. Such a stage occurs in a transition between a quiescent preexisting arc in the late growth phase and its poleward expansion. It is characterized by a gradual intensification and in many cases the emergence of azimuthally-spaced auroral structures, i.e., the auroral beads, along the preexisting arc. The beading arc usually has well-defined characteristic azimuthal wavelength and e-growth rate in optical intensity (Liang et al. 2008; Kalmoni et al. 2015; Nishimura et al. 2016). Despite the beading and intensification the arc shape is essentially maintained during this stage, until it is deformed by a significant poleward expansion of auroras, which marks the full expansion phase of the substorm. It is widely agreed that such a transitional stage cannot be classified into an "expansion phase"; some researchers deem it as the end of the growth phase-certain features of this transitional stage are indeed similar to the "explosive growth phase" proposed in Ohtani et al. (1992). In this study, to emphasize the difference between this transitional stage and classical late growth phase, we shall use the term "transitional stage of substorm onset" (TSSO), which was first proposed in Liang et al. (2016). Several possible mechanisms underlying the TSSO have been proposed, but no consensus has been reached yet. For example, based upon the observations in Liang et al. (2008), Liu et al. (2012) proposed a drift ballooning mode with ion Hall effects and heat flux modification. Kalmoni et al. (2015) compared a few candidate instability theories with their derived arc wave parameters, and concluded the shear flow ballooning instability (Voronkov et al. 1997) appears to best fit the observations. Lui (2016) argued that Kalmoni (2015)'s and Liang et al. (2008)'s results could also be interpreted via a cross-field current instability. Nishimura et al. (2016) used the kinetic ballooning model developed by Pritchett and Coroniti (2013) to interpret their auroral beads/rays observations.

In principle, instruments such as THEMIS whitelight ASIs have no discrimination on electron and proton auroras. However, due to the dominance of electron auroras in optical intensity, the above studies on TSSO based upon whitelight auroral images allude almost exclusively to electron auroras. Mende et al. (2001, 2003) compared the electron and proton auroras during substorms using IMAGE satellite observations, and noticed that the proton auroras show less variation as compared to the electron auroras, but their results were somehow limited by the low spatial and temporal ( $2 \mathrm{~min}$ ) resolution of the auroral instruments onboard IMAGE. So far to the authors' knowledge, a dedicated study on the proton auroral variation during the TSSO is absent in the existing literature; it will be the main research target in this study.

The proton aurora is a hydrogen emission led by the proton precipitation. The principal pitch-angle diffusion process of magnetospheric protons results from the nonadiabatic, chaotic motion of ions under curved magnetic field geometry (e.g., Sergeev et al. 1983; Donovan et al. 2003; Yue et al. 2013). When energetic protons from the magnetosphere bombard the Earth's atmosphere they undergo charge exchange collisions with atmospheric particles and become excited neutral hydrogen. Proton auroral photons are emitted from these excited neutral hydrogen atoms. Subsequent collisions re-ionize and reneutralize the hydrogen atom/proton, so that a single incident proton may give rise to many hydrogen emission photons. Since a neutral hydrogen atom is not magnetized, these ionization/neutralization sequences may cause the drifting of the proton away from the field line that it was incident on, leading to a broadening of spatial scales of the precipitating proton structure (Davidson 1965; Fang et al. 2004). We shall specifically discuss the potential effect of such spatial spreading on our approach and results in "Discussion" section. The brightest emissions are the Hydrogen Balmer $\alpha$ and $\beta$ and Lyman $\alpha$ emissions. Lyman $\alpha$ is the brightest of the three; it has been used in space, e.g., with the Spectroscopic Imager on the IMAGE satellite (Mende et al. 2001, 2003), but is not useful for observations from the ground because of atmospheric absorption. For ground-based observations, the Balmer $\alpha$ is brighter than the Balmer $\beta$ (hereafter referred to as $\left.\mathrm{H}_{\beta}\right)$, but is too close to other $\left(\mathrm{N}_{2} 1 \mathrm{P}\right.$ bands) bright electron auroral emissions. Therefore, in almost all practical ground-based proton auroral measurements, including those to be used in this study, the $\mathrm{H}_{\beta}$ $486.1 \mathrm{~nm}$ emission line is adopted. Readers are referred to Donovan et al. (2012) for a review on the general properties and ground-based observations of proton auroral emissions.

The $486.1 \mathrm{~nm}$ proton auroral intensity is usually about 2 or more orders of magnitude weaker than the $557.7 \mathrm{~nm}$ electron auroral intensity for a typical substorm arc. However, since proton auroras are directly related to the energetic proton precipitation from the central plasma sheet (CPS), their observations provide a valuable remote-sensing tool for the studies on the configuration and dynamics of the CPS. For example, the preexisting and onset arc is usually situated at the poleward "shoulder" of the main proton auroral band (Samson et al. 1992). This has helped establish the notions that the preexisting arc maps to a nightside transitional region (NTR) from a tail-like to a dipole-like configuration in 
the near-Earth CPS, and that such a NTR is where a substorm onset usually initiates (e.g., Lui and Burrows 1978; Samson et al. 1992; Liang et al. 2009; Donovan et al. 2012; Jiang et al. 2012; Yue et al. 2015). The above notions have gained increasing consensus among substorm researchers, as observed by the authors in the recent 13th International Conference on Substorms (ICS-13). Spanswick et al. (2017) investigated the magnetospheric sources of the main proton aurora band using THEMIS in situ data, and found that the bright proton auroras rarely map to beyond $10 R_{E}$ downtail. The magnetospheric root of the arc and in turn the onset location should not be much farther tailward of such a radial distance. Proton auroras were also used in many other substorm-related researches. To enumerate a few, Liu et al. (2007) found that proton auroras tend to fade moderately during the last several minutes of the growth phase in many events. Gilson et al. (2012) simulated the proton auroral response to substorm dipolarizaion. Donovan et al. (2012) and Liang et al. (2013) adopted multi-probe measurements to evaluate the in situ field line-curvature and used this information and proton auroras in M-I mapping during substorm intervals. Ge et al. (2012) reported the proton auroral features that might be associated with bursty bulk flows and dipolarization fronts in the tail.

In this study, we shall investigate the proton auroral variations during the TSSO, and compare them to the concurrent electron auroras at the same latitude, longitude, and time interval. The paper is organized as follows. We shall first describe the instruments, particularly the proton auroral instruments used in this study. We shall then introduce a few event examples, and present a superposed epoch analysis of 12 events investigated. We found that, while the electron auroral arc usually enhances by a few times or even an order of magnitude during the TSSO, there is little accompanying proton auroral variation. We then discuss the potential implication of our finding on the exploration of the potential mechanisms of the TSSO and in turn of the substorm onset.

\section{Instruments}

The major instrument to be used in this study is the meridian scanning photometer (MSP). MSP is an instrument that collects photons of specified wavelengths while scanning a longitudinal meridian. The data used in this study cover three generations of MSPs that are deployed by the Auroral Imaging Group at the University of Calgary. The legacy MSP instrument was operated from 1987 to 2011. After that, MSPs with new electronics and optics were re-deployed and are still working today. These MSPs sample $577.7 \mathrm{~nm}$ and $630 \mathrm{~nm}$ Oxygen lines, $486.1 \mathrm{~nm}$ $\mathrm{H}_{\beta}$ proton auroral emissions, $470.9 \mathrm{~nm} \mathrm{~N} \mathrm{~N}_{2}$ emission line, and four addition channels for background subtraction, in a time resolution of $\sim 30 \mathrm{~s}$ per scan. The $557.7 \mathrm{~nm}$ green-line is chosen as representative of electron auroras in this study. Since those MSPs are designed for multiwavelength observations, they are equipped with rotating filter wheels. Sample gating reduces the signal, which may be crucial for the weak proton auroral emissions. Forty-eight sixty-one (FESO) was specially designed for proton auroras. It duplicates the scanning pattern and period (30 s) of the refurbished MSP, but is designed to allow simultaneous signal and background measurement without the rotating filter wheel, therefore enhancing sensitivity. The scan steps required for $\mathrm{H}_{\beta}$ sampling to accumulate to a reliable signal/noise ratio are reduced for FESO, hence improving the latitudinal resolution. In this study, we shall use FESO data at Athabasca, which has been operating since 2014. All the MSP and FESO data included in this study are preliminarily calibrated. Background subtraction and elevation angle dependence are processed, yet the conversion factors to absolute Rayleigh values have not been finally determined. However, except for occasional noises the relative variations of both electron auroras and proton auroras measured by MSP and FESO, which are the research interest of this study, are trustworthy.

To examine the context of the substorm onset and, more importantly, to identify the TSSO, all-sky imager (ASI) observations are required for this study. Also, for events with FESO conjunction only (i.e., without MSP $557.7 \mathrm{~nm}$ data) the ASI raw intensity is to be used as a proxy of electron auroras. The ASIs (Mende et al. 2008) of the Time History of Events and Macroscale Interactions during Substorms (THEMIS) project are primarily used in this study. THEMIS ASI captures whitelight auroral images in 3-s cadence with exposure time of $1 \mathrm{~s}$. For two of our events when the THEMIS ASI data are not available, we resort to Rainbow ASI observations (Jackel et al. 2014). Rainbow ASI is a digital camera that includes three color channels (red, green, and blue), operating with 5-s exposure at a 6-s cadence.

Our event selection criteria are as follows. (1) We survey and select substorm events with distinctly recognizable TSSO features, from ASI observations that have MSP conjunction at Gillam or Fort Smith, or FESO conjunction at Athabasca. (2) The FESO/MSP scan meridian must be well within the onset sector, and the proton auroral data during the event interval of interest must be of decent quality. (3) Considering the FESO/MSP time resolution, the TSSO interval must be longer than $1 \mathrm{~min}$, so that it contains at least two FESO/MSP proton auroral data points. (4) If not otherwise indicated (see "2016-12-09 0703 UT substorm onset" section), the emission height for both electron auroras and proton auroras is assumed 
to be $110 \mathrm{~km}$ in this study, and the AACGM coordinate with IGRF12 coefficients is used in defining the magnetic latitude (MLAT) and magnetic longitude (MLON).

\section{Observations}

In the following section, we shall first present a few event examples on the proton auroras during the TSSO. We have selected these events on the basis of both scientific and instrumental considerations. Via these events, we shall introduce our main research objective and data processing procedures involving various instruments. A superposed epoch analysis will then ensue.

\section{1-10-02 0457 UT substorm onset}

We choose this event to present for a few purposes. (1) The event has the ideal combination of instruments, namely the THEMIS ASI and MSP multi-wavelength optical measurements. In particular, MSP data contain the calibrated 557.7 green-line intensity, the dominant electron auroral emission, in the same time bins and elevation angle bins as the proton aurora, facilitating a direct comparison between them. (2) We shall use this event to demonstrate the typical features of the TSSO. (3) We shall illustrate our techniques and procedures to determine the start and end times of the TSSO, denoted $T 1$ and T2, as described in detail below, more specifically, $T 0$ and $T 1$ (see details below). (4) We shall introduce our procedure in comparing proton auroras and electron auroras during the late substorm growth phase and the TSSO.

Figure 1 shows a few selected THEMIS auroral images showing the substorm onset. There is a preexisting growth phase arc (Fig. 1a), which gradually intensifies after 0455:30 UT, At 0456 UT, the arc has been moderately intensified (Fig. 1b) and, on a close look one may marginally see some weak wave-like structure along the arc. Those auroral beads become very evident at 0457 UT (Fig. 1c, d). One may notice that those beads appear to protrude a little bit north of the initial arc latitude, but a careful examination reveals that those protruding structures are all ray-like. In this event, the arc is a little bit off zenith ( $\sim 4^{\circ}$ Elev.). We suggest that, when the arc beads intensification proceeds during the TSSO, the precipitating electron spectra harden a little bit so that the aurora beads extend to lower altitudes, producing a ray structure and hereby an alias of "poleward protruding", in an image map assuming a constant emission altitude $(110 \mathrm{~km}$ in this case). Unambiguous evidence of the poleward auroral expansion is seen at 04:57:33 UT, when non-ray-like auroras above the preexisting arc latitude clearly exist (labeled by red arrow in Fig. 1e) near the MSP meridian. After then the auroras strongly brighten and quickly move poleward in the next minute, signifying the substorm expansion phase (Fig. 1f).
We hereby emphasize one key criterion of our event selection. For our research purpose, the MSP (or FESO if it is used instead) meridian must be well within the initial expansion onset sector. More specifically, (1) the MSP meridian is within $\pm 5^{\circ} \mathrm{MLON}$ of the starting longitudes of the poleward auroral expansion and, (2) the time difference between the initial signature of the poleward expansion and the start time of the poleward expansion seen in the MSP meridian is $\leq 15 \mathrm{~s}$, as compared to the $30 \mathrm{~s}$ resolution of MSP instruments involved in this study.

We then construct the auroral keogram along the MSP scan line. This is done by sampling THEMIS ASI pixels around $\pm 0.25^{\circ}$ MLON at each latitude along the MSP meridian. The output is shown in the top panel of Fig. 2a. We apply a semi-automatic algorithm developed in Uritsky et al. (2009) to identify the arc band from auroral images. The arc band is identified and changed for every minute till the expansion phase starts. Upon a careful examination of the raw image sequence and the keogram, we may identify $T 1$, the start time of a significant poleward expansion of auroras above the preexisting arc band. In practice, we choose $T 1$ as the time epoch when auroras visibly extend (not ray-like) to $>0.2^{\circ}$ MLAT above the preexisting arc and show a continuous trend of poleward expansion afterward. In this case, $T 1$ is determined to be 04:57:33 UT. To identify $T 0$, we sample the auroral intensity within the arc band, and plot them in the lower panel of Fig. 2a. T0 is determined as the start of notable increase of arc intensity above the growth phase level and noises. The above-determined $T 0$ and $T 1$ are marked as vertical dotted lines in Fig. 2a. TSSO is by definition, the interval between $T 0$ and $T 1$. For a substorm with well-defined TSSO features (our event selection criterion), the ambiguity in the determination of $T 0$ and $T 1$ is usually much smaller than $30 \mathrm{~s}$, the temporal resolution of MSP and FESO. Note that we have kept the arc sampling latitude being constant after $T 1$, regardless of the subsequent auroral expansion. Our sampled arc intensity is meaningful during the late growth phase and the TSSO, yet may not apply to the post-onset expansion phase auroras - they are not our research interest in this study, and as a matter of fact there is often no longer well-defined arc structure by that time.

Figure $2 \mathrm{~b}$ shows the MSP observations. The upper panel presents the $557.7 \mathrm{~nm}$ green-line emission. These data have been preliminarily calibrated into optical Rayleigh values, though still subject to an undetermined factor presumably no more than 2 . The relative change of the intensity is fully trustworthy. The lower panel of Fig. $2 \mathrm{~b}$ shows the $486.1 \mathrm{~nm} \mathrm{H}_{\beta}$ proton emission, with the electron aurora arc band marked. The arc is located on a poleward decreasing slope of the proton auroral intensity, between the main proton auroral band and the dark 

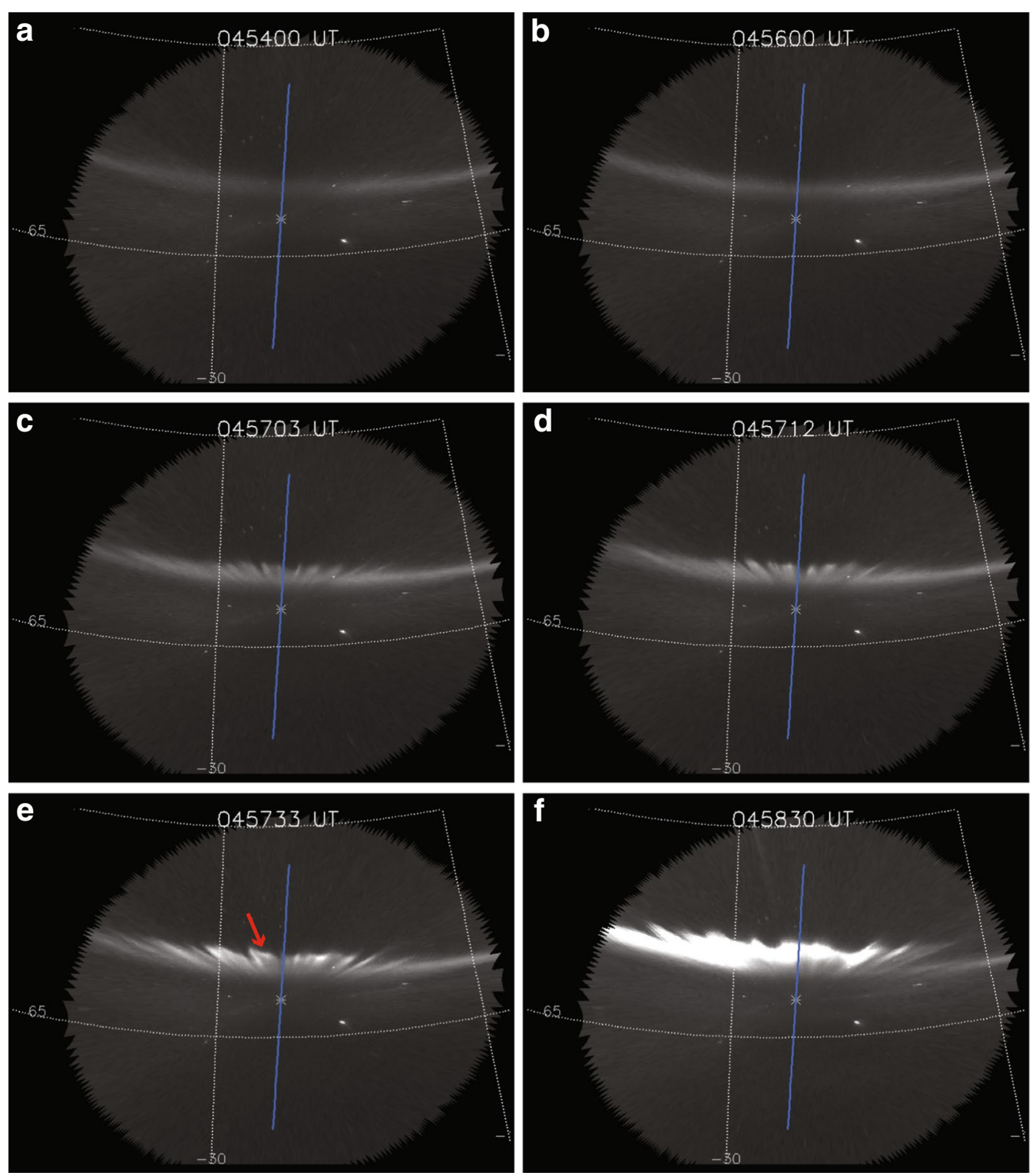

Fig. 1 THEMIS ASI images showing substorm onset on 2011-10-02. A few selected THEMIS ASI images showing the substorm onset on 2011-10-02. The images are mapped in AACGM coordinate by assuming an emission height of $110 \mathrm{~km}$. A blue line in each figure marks the MSP scan line. A white asterisk marks the zenith of the ASI. The images are indexed to facilitate referene in the text

region poleward of it. In a more depictive word, the arc is located at the poleward "shoulder" of the main proton auroral band (Samson et al. 1992; Donovan et al. 2012). This has been well established as a robust feature of the preexisting arc during the late growth phase of substorms (see "Introduction" section).

To directly compare the electron auroras and proton auroras, we sample and average the MSP $557.7 \mathrm{~nm}$ data and $486.1 \mathrm{~nm}$ data in the latitudinal band of the arc. The outcome is shown in Fig. 3. We also reproduce the THEMIS ASI arc intensity obtained from our previous procedure in the top panel. A key point in our approach is that, we are to compare the electron auroras and proton auroras at the same latitudes (arc band), same longitude (MSP meridian, note that the THEMIS ASI counts is also sampled around this meridian), and the same time interval (late growth phase and TSSO). Via this approach, we circumvent the field line-mapping difficulty, and look into the same region in the tail, i.e., the magnetospheric "root" of the preexisting arc where the substorm onset initiates, for electron and proton auroras. The variations of the arc intensity obtained from the MSP $557.7 \mathrm{~nm}$ and from the THEMIS ASI essentially agree with each other, except that the temporal resolution of the former 


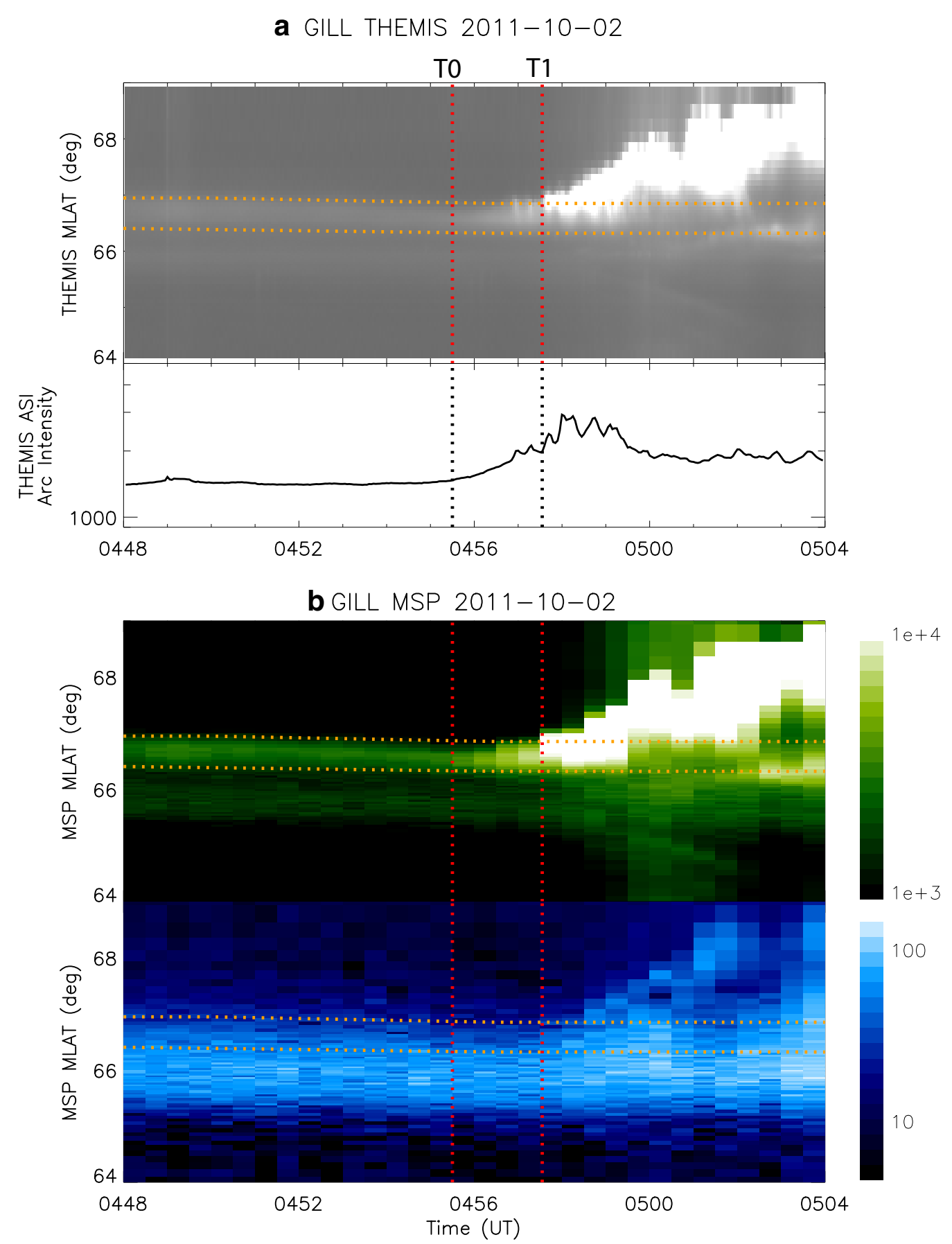

Fig. 2 THEMIS ASI keogram and MSP observations. Top panel of a shows the THEMIS ASI keogram constructed along the MSP scan line. The arc band is shown in orange dotted lines. The lower panel of a shows the ASI counts sampled and averaged over the arc band along the MSP scan line. In $\mathbf{b}$, the upper and lower panels show the 557.7 green-line intensities and $486.1 \mathrm{~nm}$ proton auroral intensities, versus time and latitude. The arc band is also labeled. Two vertical dotted line throughout the plot denote TO and T1, the TSSO intervals

is lower. Both instruments indicate that electron auroras increase substantially during the TSSO. In contrast, there is no hint of enhancement in proton auroras during the TSSO. As a matter of fact, the proton auroras sampled in the arc band (3rd panel of Fig. 3) appears to be slightly decreased during the TSSO. One possible cause of such a slight decrease might be the enhancement of upward electric field in the auroral acceleration region during the TSSO, which is partly hinted by the appearance of raylike auroras (implying an extension of precipitation flux 


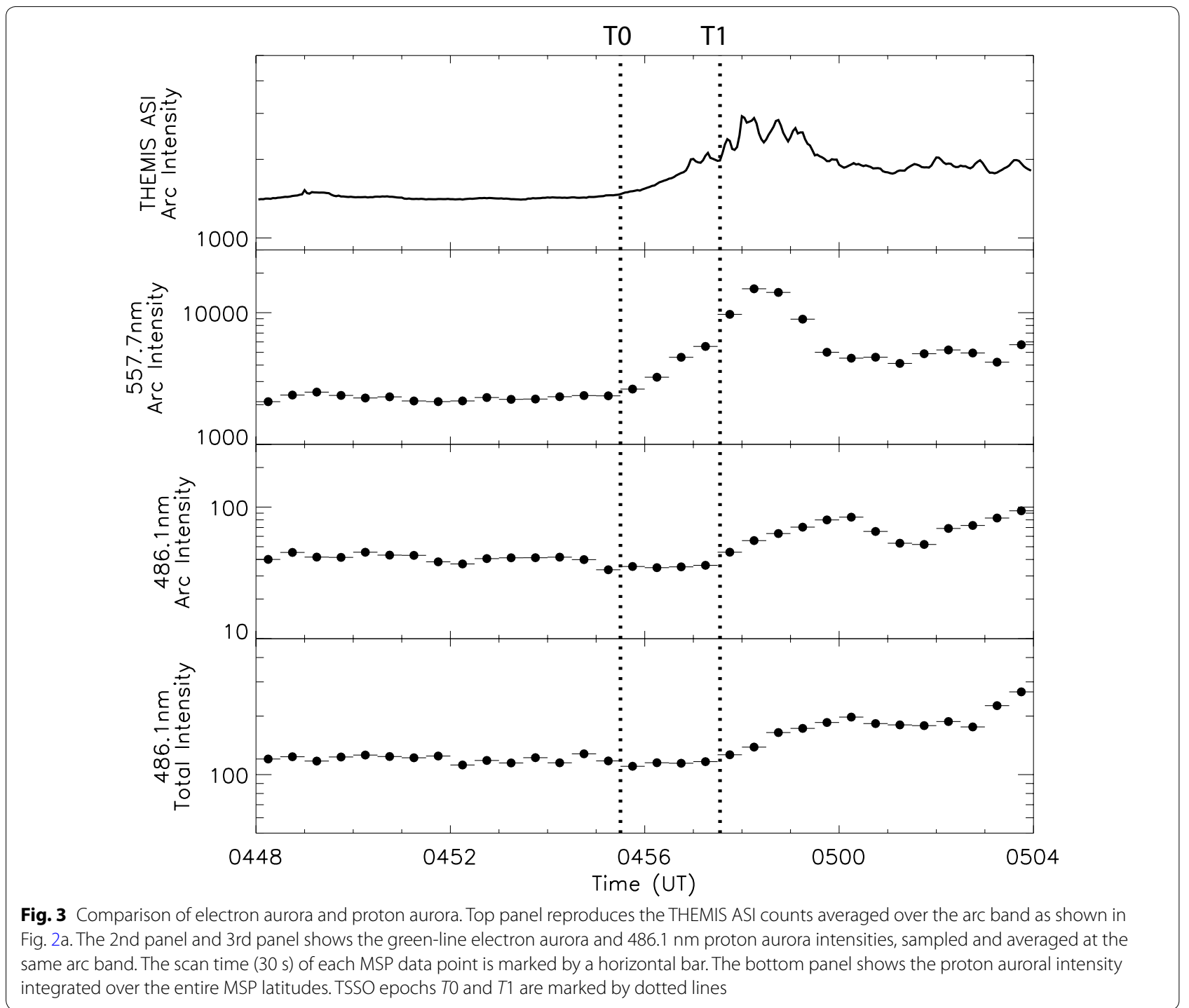

spectra to higher energies) during the TSSO in this event. The bottom panel of Fig. 3b shows the integrated proton auroral intensity over the entire latitudinal range of MSP. This parameter may to a certain degree reflect the variations of the total energetic ion fluxes integrated over the CPS. We again confirm that there is no notable variation of the total proton auroral intensity, much less any clue of enhancement, during the TSSO. Substantial intensification of proton auroral intensity occurs only after $T 1$.

Though not of the core interest of this paper, we note an interesting feature of proton auroras during the early expansion phase of the substorm: there appears to be a poleward-propagating trace after $T 1$, which stems from the latitudes of the preexisting arc band. Such a trace appears to be somehow disjointed from the main proton auroral band (see more clearly in the next event example).

\section{5-03-18 0725 UT substorm onset}

We shall use this event to introduce the FESO instrument. This event occurred during the St Patrick's geomagnetic storm interval, but itself was a well-defined isolated substorm. Figure 4 shows a few THEMIS ASI images showing the substorm onset. A blue line marks the FESO scan line. The onset stems from a preexisting growth phase arc (Fig. 4a). After 0723 UT, some weak wave-like intensification begins to emerge at the poleward portion of the preexisting arc (marginally discernible in Fig. 4b). The aurora beads grow in intensity and size, and become fairly visible after 0724 UT (Fig. 4c, d). Noticeable poleward expansion starts after 07:25:15 UT; an initial signature of such a poleward expansion can be seen immediate east of the FESO meridian (Fig. 4e). The auroras then strongly brighten and quickly move 

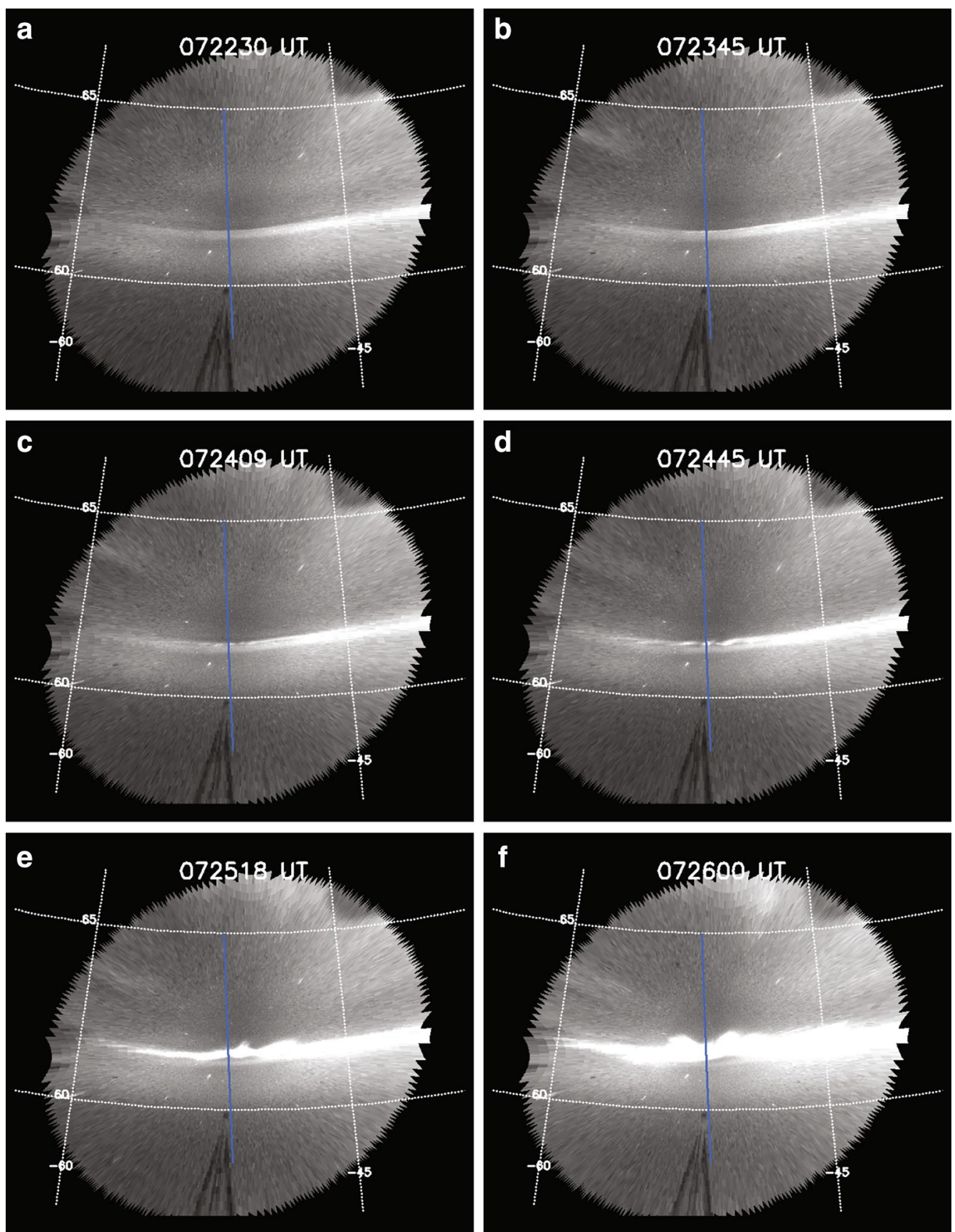

Fig. 4 THEMIS ASI images showing substorm onset on 2015-03-18. A few selected THEMIS ASI images showing the substorm onset on 2015-03-18. The format is the same as Fig. 1, except that the blue line here denotes the FESO scan meridian. The images are indexed to facilitate referene in the text

poleward in the next minute, signifying the substorm expansion phase (Fig. 4f).

Following the above-depicted procedure, we construct the auroral keogram along the FESO scan line and show it in the upper panel of Fig. 5a. We sample the auroral intensity within the arc band and $\pm 0.25^{\circ}$ MLON around the FESO meridian and plotted them in the lower panel of Fig. 5a. Note that in this event, since the very initial brightening is fairly weak. When the beading structures propagate eastward so that the peak and gap of the beads alternately pass over the FESO meridian, the sampled arc intensity features some notable fluctuations. Figure $5 \mathrm{~b}$ 

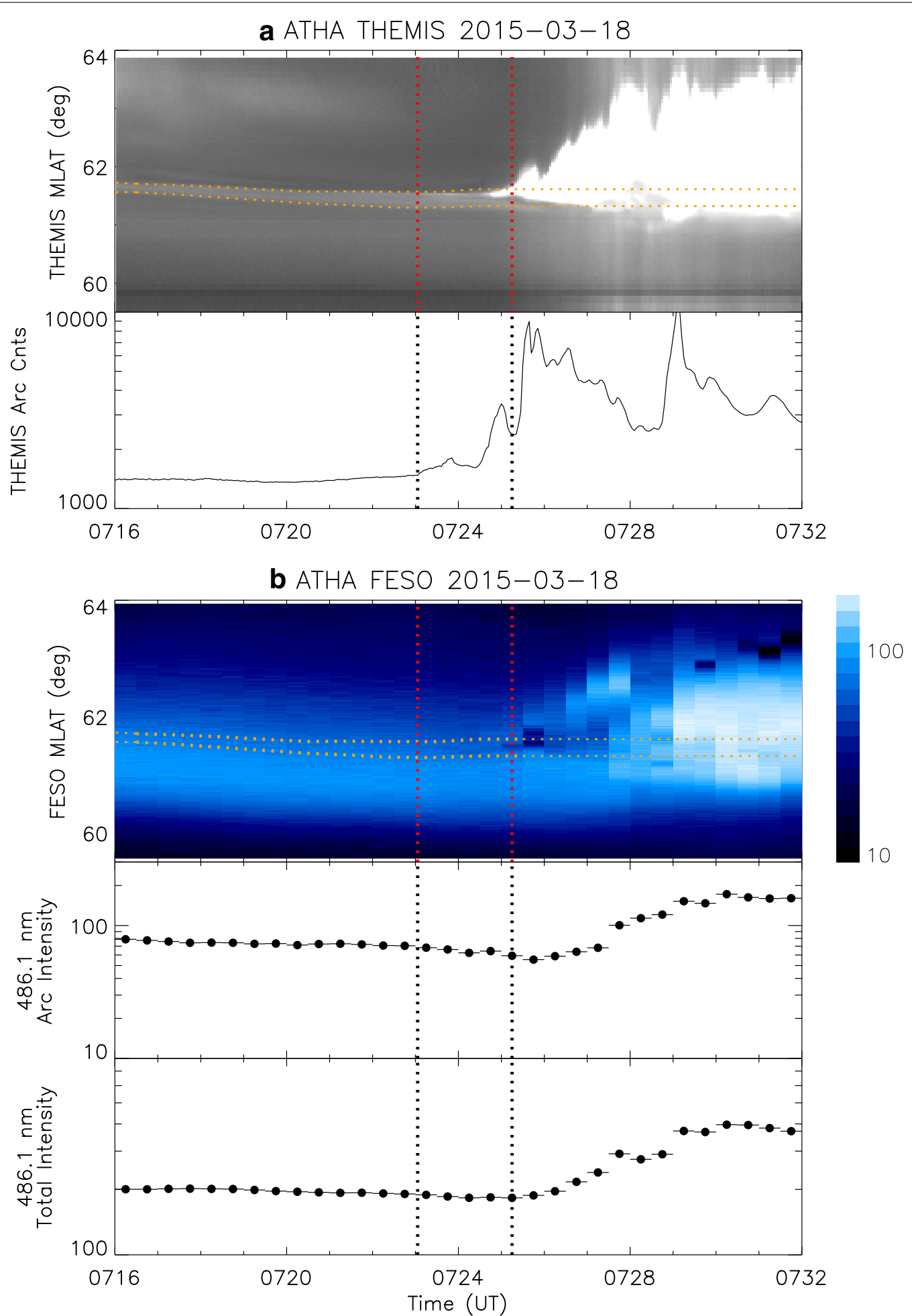

Fig. 5 THEMIS ASI observations and FESO proton auroral observations. Top panel of a shows the THEMIS ASI keogram constructed along the FESO scan meridian. The arc band is shown in orange dotted lines. The lower panel of Fig. 2a shows the ASI counts sampled and averaged over the arc band along the FESO meridian. In Fig. 2b, the top panel shows the FESO $486.1 \mathrm{~nm}$ proton auroral intensities versus time and latitude, with the arc band overploted. The 2nd and bottom panel of $\mathbf{b}$ show the proton auroral intensities averaged over the arc band, and the total proton auroral intensities integrated over full FESO latitudes, respectively. The scan time (30 s) of each FESO data point is marked by a horizontal bar. Two vertical dotted line throughout the plot denote TO and T1, the TSSO interval 
shows the FESO observations. We have labeled the arc band, as well as $T 0$ and $T 1$ in the plot. Again the arc is located on a poleward shoulder of the main proton auroral band. One may readily see that the proton auroras do not show any noticeable variation during the TSSO. Significant brightening of proton auroras occurs a few minutes after $T 1$. To make a quantitative check, we again integrate the proton aurora over the preexisting arc band as well as over the entire FESO latitudinal range. The results are shown in the bottom two panels of Fig. 5b. Again, neither the arc-averaged proton auroral intensity nor the total proton auroral intensity shows appreciable variations during the TSSO.

Note that in this event we again see the polewardprogressing trace, which stems from the latitude of the preexisting arc after $T 1$, and gradually intensifies while propagating poleward. Such a poleward-propagating trace appears to be disjointed from the main proton auroral band, and there is actually a minimum of emission intensity between such a poleward trace and the main proton auroral band. Strong intensification of the main proton auroral band occurs near the end of the poleward-progressing trace. We have also seen such a feature in a number of other events. Since this paper is focused on the late growth phase and the TSSO, proton aurora features after $T 1$ are not our research object here, but we plan on a dedicated investigation on such poleward-progressing traces in a separate publication in the near feature.

\section{6-12-09 0703 UT substorm onset}

In optical auroral observations, the uncertainty of emission height may introduce ambiguity in positioning an auroral structure, particularly under the circumstance of low elevation-angle observations. The issue may be more challenging for our research interest, since we are to compare the electron aurora with the proton aurora. For typical electron auroral precipitation and proton auroral precipitation with characteristic energy of $\mathrm{keV}$ and $\sim 10 \mathrm{keV}$, respectively, their peak emission altitudes are presumably close to each other $(\sim 100-120 \mathrm{~km}$, e.g., Galand et al. 1997), so that the error in comparing the locations of electron auroras and proton auroras may not be significant $\left(<\sim 0.1^{\circ} \mathrm{MLAT}\right)$ as long as the observation is not too far away from the zenith ( $>45^{\circ}$ elevation), which is the case for $7 / 12$ of our investigated events (see Table 1). However, such errors would certainly become more serious at low elevation angles. That said, we shall exemplify an event in this subsection to demonstrate that, despite the intrinsic limitation of low-elevation

Table 1 Substorms investigated in this study

\begin{tabular}{|c|c|c|c|c|c|c|}
\hline Date & Arc MLAT & MSP arc elev. & TO (UT) & $T 1$ (UT) & $\begin{array}{l}\text { Proton aurora } \\
\text { instrument }\end{array}$ & Electron aurora instruments \\
\hline \multirow[t]{2}{*}{ 2008-03-05 } & $66.2^{\circ}$ & $81.9^{\circ}$ & 06:03:33 & 06:06:51 & GILL MSP & GILL THEMIS ASI \\
\hline & & & & & & GILL MSP \\
\hline \multirow[t]{2}{*}{ 2010-04-15 } & $67.2^{\circ}$ & $86.8^{\circ}$ & 05:55:06 & 05:57:09 & FSMI MSP & FSMI THEMIS ASI \\
\hline & & & & & & FSMI MSP \\
\hline \multirow[t]{2}{*}{ 2011-04-21 } & $66.6^{\circ}$ & $53.6^{\circ}$ & 05:07:33 & 05:08:51 & GILL MSP & GILL THEMIS ASI \\
\hline & & & & & & GILL MSP \\
\hline \multirow[t]{2}{*}{ 2011-10-02 } & 66.6 & $53.8^{\circ}$ & 04:55:30 & 04:57:33 & GILL MSP & GILL THEMIS ASI \\
\hline & & & & & & GILL MSP \\
\hline \multirow[t]{2}{*}{ 2013-03-09 } & 66.9 & $70.5^{\circ}$ & 07:07:12 & 07:08:18 & FSMI MSP & FSMI THEMSI ASI \\
\hline & & & & & & FSMI MSP \\
\hline \multirow[t]{2}{*}{ 2013-10-07 } & $65.8^{\circ}$ & $35.9^{\circ}$ & 06:16:06 & $06: 18: 36$ & FSMI MSP & FSMI THEMIS ASI \\
\hline & & & & & & FSMI MSP \\
\hline \multirow[t]{2}{*}{ 2014-03-03 } & $64.8^{\circ}$ & $45.4^{\circ}$ & 06:15:39 & $06: 17: 12$ & GILL MSP & GILL THEMIS ASI \\
\hline & & & & & & GILL MSP \\
\hline 2015-03-18 & 61.5 & $82.7^{\circ}$ & 07:23:03 & $07: 25: 15$ & ATHA FESO & ATHA THEMIS ASI \\
\hline \multirow[t]{2}{*}{ 2016-08-10 } & 64.1 & $<20^{\circ}$ & $06: 14: 33$ & 06:15:54 & ATHA FESO & ATHA Rainbow ASI \\
\hline & & & & & & FSMI THEMIS ASI \\
\hline \multirow[t]{2}{*}{ 2016-09-08 } & 63.4 & $27.7^{\circ}$ & 06:03:30 & 06:04:51 & ATHA FESO & ATHA Rainbow ASI \\
\hline & & & & & & FSMI THEMIS ASI \\
\hline 2016-09-29 & $63.1^{\circ}$ & $34.8^{\circ}$ & $04: 24: 18$ & $04: 25: 18$ & ATHA FESO & ATHA THEMIS ASI \\
\hline \multirow[t]{2}{*}{ 2016-12-09 } & $64.7^{\circ}$ & $<20^{\circ}$ & 07:01:33 & 07:03:15 & ATHA FESO & ATHA THEMIS ASI \\
\hline & & & & & & FSMI THEMIS ASI \\
\hline
\end{tabular}


measurements, some useful information on the proton auroral variation during the TSSO may still be inferred.

Figure 6 shows a few selected images showing the substorm onset. The image maps are built upon ASI observations from two adjacent stations, one at Athabasca (ATHA, the lower-latitude one) and the other at Fort Smith (FSMI, the higher-latitude one). The growth phase arc is observed in the overlapping area of the field-ofview (FoV) of two ASIs, enabling us to evaluate the emission height of the arc via an triangulation technique (e.g., Jackel et al. 2003) - and the best fit height is found to be $\sim 100 \mathrm{~km}$. The presented auroral images are built upon this inferred emission height. While the arc is at the edge of the ASI FoV so that the wave-like beading structure tends to be deformed in the projected map, one may still notice their existence, e.g., at 07:02:39 UT (Fig. 6b). The poleward expansion of auroras is better viewed in the FSMI FoV, and the initial clue of a noticeable poleward expansion is found at 07:03:15 UT (Fig. 6c), which is the start of subsequent expansion phase (Fig. 6d). In the other $<20^{\circ}$ low-elevation-angle case (2016-08-10 event) and a marginal case (2016-09-08 event), we have performed similar routines and involved ASIs at both ATHA and FSMI to help determine the arc band and the TSSO.

Following the above-depicted procedures, we construct the auroral keogram for both FSMI ASI (the top panel of Fig. 7) and ATHA ASI (the 2nd panel). Note that the $y$-axis denotes elevation angle here. We identify
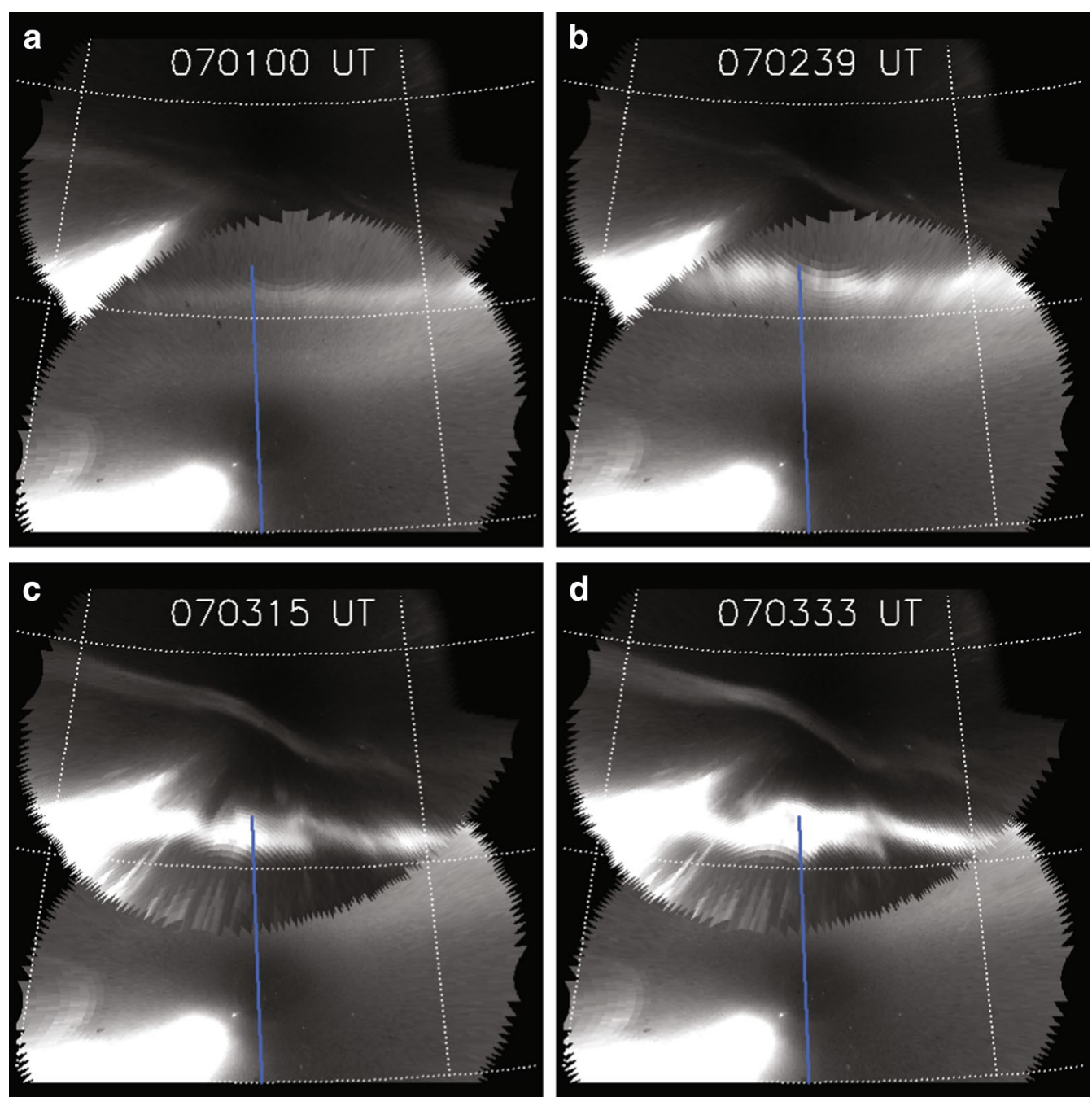

Fig. 6 THEMIS ASI images showing substorm onset on 2016-12-09. A few selected auroral images from ATHA ASI (lower-latitude one) and FSMI ASI (higher-latitude one) showing the substorm onset on 2016-12-09. An emission altitude of $100 \mathrm{~km}$ is used here based upon a triangulation technique of the arc in the overlapping area of two ASIs. A blue line denotes the FESO scan meridian. The images are indexed to facilitate referene in the text 


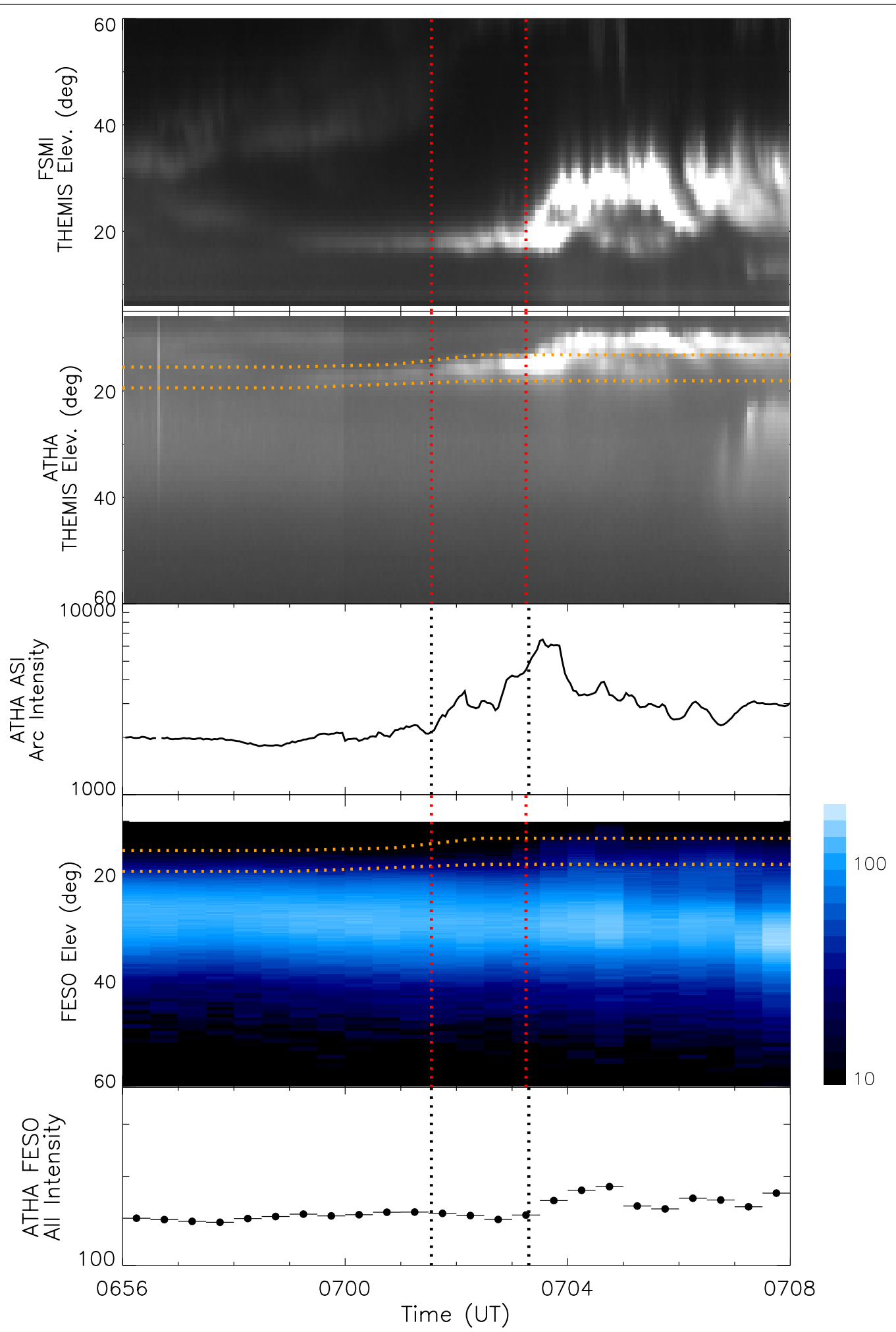

Fig. 7 THEMIS ASI observations and FESO proton auroral observations. The top two panels show the FSMI ASI keogram and ATHA ASI keogram constructed along the FESO meridian, respectively. The arc band is shown in orange dotted lines in the 2nd panel. The 3rd panel shows the ATHA ASI counts sampled and averaged over the arc band. The 4th panel shows the FESO proton auroral intensities versus time and latitude. The bottom panel shows the total proton auroral intensities integrated over full FESO latitudes. Two vertical dotted line throughout the plot denote $T 0$ and $T 1$, the TSSO interval 
elevation angle range of the arc (orange dotted line in the 2nd panel) and sample the arc intensity, and show in the 3rd panel of Fig. 7. Based upon the above observations, despite the difficulty in low-elevation-angle measurement $T 0$ and $T 1$ can still be inferred with some confidence. The 4th panel of Fig. 7 shows the FESO (collocated at ATHA) proton auroral observation. We also overplot the elevation angle band of the arc in this panel for inference. One may notice that, while the arc is also located poleward of the main proton auroral band, the former appears to be a bit more detached from the latter than in previous examples. This is very likely an altitude-latitude alias. We have evaluated from a triangulation technique between FSMI and ATHA ASIs that the emission height of the arc is $\sim 100 \mathrm{~km}$; the emission height of the proton aurora might be a bit higher. Thus, even though their actual latitudinal separation may not be very large, their separation in elevation angle is exaggerated due to the lower emission height of the arc.

Such height-latitude alias imposes difficulties on our efforts to compare electron and proton auroras in the same arc region. We have made a numerical test and infer that, if the emission height is $\pm 10 \mathrm{~km}$ off $110 \mathrm{~km}$, the default emission altitude applied in this study, the offset of the mapped latitudes of the arc would be $\pm 0.15^{\circ}$ MLAT when the arc elevation is $30^{\circ}$, yet increase to $0.23^{\circ}$ MLAT when the elevation angle is $20^{\circ}$. Together with another observation that the mean arc width is $\sim 0.33^{\circ}$ inferred from our events with elevation $>45^{\circ}$, we conclude that, an attempt to compare an electron arc intensity and the proton aurora in the same latitude range becomes marginal when the elevation drops below $30^{\circ}$, and almost unjustifiable when the elevation angle is $<20^{\circ}$. Therefore, we will not try to investigate the proton auroral variation corresponding to the electron auroral arc band for this event and one other event with $<20^{\circ}$ lowelevation angle (see Table 1).

That said, some useful information on the proton auroral variation during the TSSO may still be inferred. It can be seen from the 4th panel of Fig. 7 that, while we may not accurately locate the actual arc band in proton auroral observations due to uncertain emission height, we nevertheless note that, throughout the poleward portion of the main proton auroral band where the arc is supposed to be situated around, the intensity shows no substantial variation during the late growth phase and the TSSO. The bottom panel of Fig. 7 shows the total proton auroral intensity integrated over all FESO latitudes. Note that this total proton auroral intensity may remain meaningful since the latitudinal integral process may largely relieve the uncertain of emission height. The total proton auroral intensity appears to decrease slightly during the TSSO, and shows moderate intensification after $T 1$. We have also checked the other $<20^{\circ}$ low-elevation-angle event in a similar way and confirmed that the information on the lack of proton auroral variations during the TSSO can also be drawn.

\section{Superposed epoch analysis}

So far we have collected and analyzed 12 substorm onset events, which are listed in Table 1 . In most cases, the preexisting arc band, $T 0$ and $T 1$ can be readily defined with little ambiguity, but there are two complications that need to be addressed here. (1) Occasionally, the substorm onset seems to stem from a newly emerged arc that appears only a few minutes before the onset (e.g., 2013-10-07 event), instead of a long-standing growth phase one. This type of event was also noticed in Lyons et al. (2002). In such cases, the concept of "preexisting arc" may become questionable, but it does not impede our research interest. (2) Occasionally, the arc intensity shows nontrivial fluctuations during the growth phase (e.g., 2016-09-29 event, see the orange curve with the most noticeable growth phase variations in Fig. 8a), imposing uncertainty to the identification of $T 0$. In those cases, we resort to an ewogram technique (e.g., Uritsky et al. 2009; Nishimura et al. 2016) from ASI observations, to look into the visible enhancement of arc beading activity to help us determine $T 0$. This is not without ambiguity, but in all of such cases the ambiguity is judged to be no larger than $30 \mathrm{~s}$, the temporal resolution of $\mathrm{FESO} /$ MSP.

To perform a superposed epoch analysis on the variation of proton auroras, we normalize the observation time $T$ according to,

\footnotetext{
(See figure on next page.)

Fig. 8 Superposed epoch analysis of electron auroral and proton auroral variations. The time ( $x$ axis) used in this plot is normalized according to Eq. (1) in the text. a The variations of electron aurora arc inferred from THEMIS or MSP $557.7 \mathrm{~nm}$ observations in 12 substorm events. $\mathbf{b}$ The proton auroral variations inferred from FESO/MSP, in the same arc band as the electron aurora. Note in (a) and (b) a shaded region indicates that the sampled intensity may no longer represent preexisting arc after T1. c Total proton auroral intensities integrated over the FESO/MSP latitudes. In (d) and (e), we show the percentage variations of the arc band proton auroral intensity and the total proton auroral intensity, relative to their mean late growth phase values (see text for details). The scan time of FESO/MSP is marked by a horizontal bar. Different colors in this figure denote different events
} 


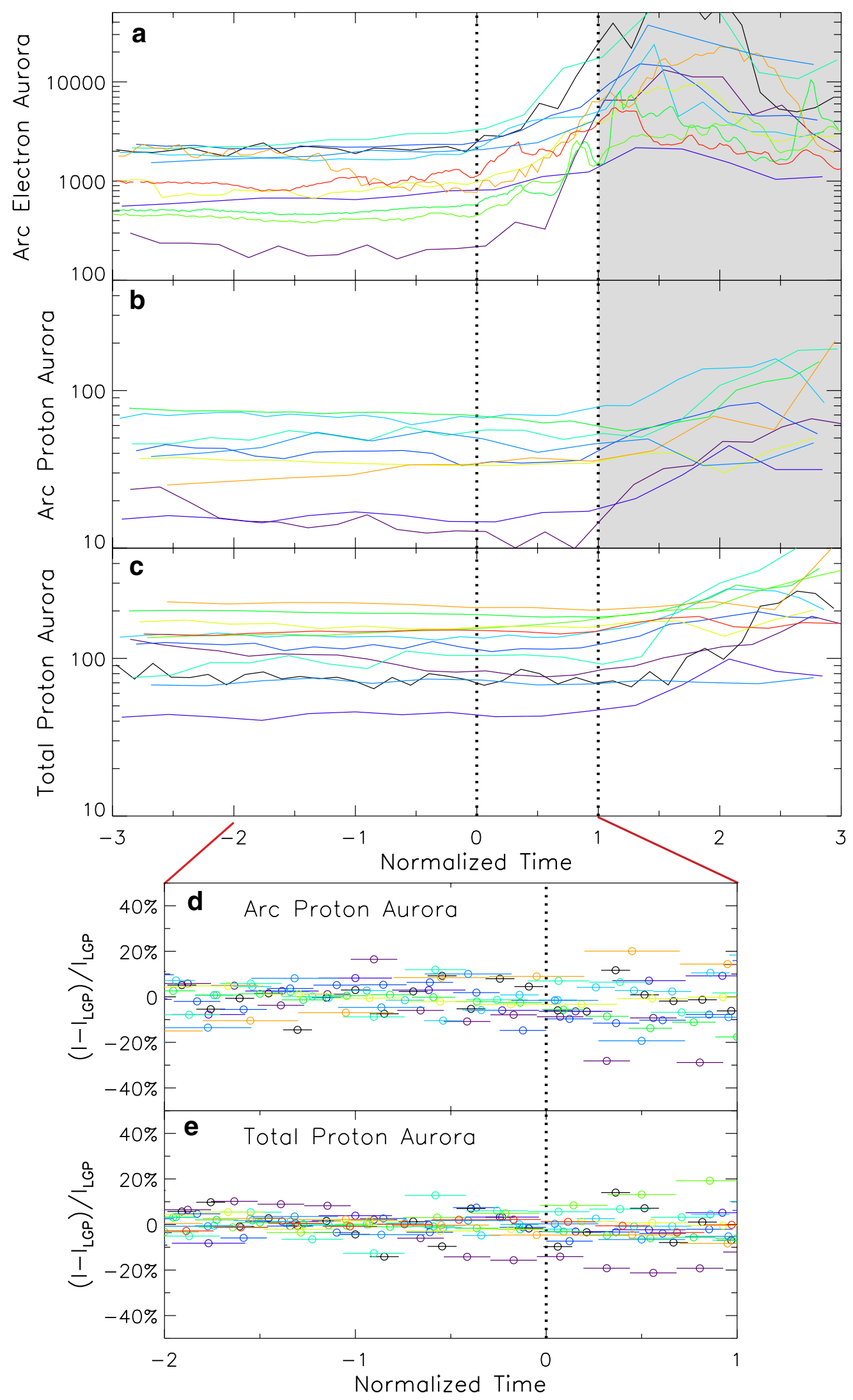




$$
T_{n}=\frac{T-T 0}{T 1-T 0},
$$

so that the TSSO epochs $T 0$ and $T 1$ project to $T_{n}=0$ and 1 , respectively. Figure 8a shows the superposition of the arc intensities from electron auroral observations. Contingent upon the event, they may come from either MSP green-line or ASI raw counts sampled in the arc band. The former data product was preliminarily calibrated into physical Rayleigh values (subject to a constant factor of no more than 2), so we keep their value intact in the plot. For the latter data product, there is no such calibration available, so that we subtract an arbitrary constant from the raw counts and display this baseline-subtracted intensity in the plot; only the relative variation of the arc intensity is informative. We remind again that, when the substorm expansion phase proceeds $(T>T 1)$, the preexisting arc is usually deformed and our procedure in sampling arc intensity may not bear much practical meaning then. Our research interest is limited to the late growth phase and the TSSO. It is clear to see that the electron auroral arc intensity features strong enhancement during $T 0$ and T1-which is part of the definition of the TSSO. Based upon MSP $557.7 \mathrm{~nm}$ observations, the optical intensity of the electron auroral arc typically increases by several times or even an order of magnitude. Since the MSP time resolution is $30 \mathrm{~s}$ only, the actual electron auroral enhancement during the TSSO is presumably even higher.

Figure $8 \mathrm{~b}$ shows the proton auroral intensity averaged in the same arc band as the electron aurora. We have excluded two $<20^{\circ}$ low-elevation-angle cases in this analysis due to the difficulty mentioned in the above subsection. As compared to the electron aurora, the proton aurora appears to be relatively dull during the TSSO. Figure $8 \mathrm{c}$ shows the total proton auroral intensity integrated over the entire MSP or FESO latitudes. Such a total proton auroral intensity may to a certain degree reflect the variations of the total energetic ion fluxes integrated over the CPS. All 12 events are included in this plot. Again, the total proton auroral intensity does not appear to show noticeable variation during the TSSO either.

To have a closer and more quantitative look into the proton auroral variations during the TSSO, In Fig. 8d, $\mathrm{e}$, we present the percentage change of the proton auroral intensity during $T_{n}=-2$ to 1 , relative to the mean late-growth-phase level in each event, The mean lategrowth-phase levels of proton auroras, $I_{\mathrm{LGP}}$ in each event is determined from the mean proton auroral intensity averaged over the interval $T_{n}=-2$ to 0 . The scan time of FESO and MSP measurements is also indicated by the extent of the horizontal bar associated with each point in this plot. Note that FESO and MSP have a fixed scan time of $30 \mathrm{~s}$, but in this plot the time is normalized according to (1). Figure $8 \mathrm{~d}$ shows the percentage variation of proton auroras averaged within the arc band, while the bottom panel denotes that of the total proton auroral intensity. As one can see, the proton auroral variations during the late growth phase and the TSSO can be either above or below the $I_{\mathrm{LGP}}$ level. Except for few outliers, the variation level during the TSSO and that during the late growth phase is fairly similar. The $\sim-30 \%$ deviation seen in the plot actually comes from one event (2010-04-15) in which the ambient proton auroral intensity is exceptionally low (see the curve with the lowest intensity in Fig. 8b), so that even though the absolute variation is small only, the percentage variation is misleadingly higher than usual. During the TSSO, in a majority (28 out of 38 ) of data points, the variations of proton auroras averaged over the arc is $<10 \%$-and the same level of variation is also common during the late growth phase. Before interpreting this result we first carefully check the potential influence of instrumental errors. Suspicious "spiky" data bins, whose values are significantly lower or higher than their adjacent bins at higher and lower latitudes, occasionally exist in MSP and FESO datasets. They are probably led by instrument errors. However, those suspicious data bins are usually isolated and tend to be smeared out in an average process over latitudes. In numerical tests, we have attempted to exclude suspicious data bins and recalculate the arc band-averaged proton auroral intensity. The general statistical pattern of the proton auroral variations is found as essentially unchanged, with no more than 5 out of 38 TSSO data points are perceptibly affected-and 3 of these 5 points actually become closer to their mean late-growth level after removing suspicious data bins. The impact of suspicious data bins on the total proton auroral intensity is even more trivial. We are thus confident that instrument errors have trivial only influence on our overall result. Many of the observed proton auroral variations might be attributed to certain physical mechanisms, e.g., some growth phase wave activities (Uritsky et al. 2009) or a continuously fading trend (Liu et al. 2007). For example, in the 2008-03-05 event (the black curve with noticeable oscillations in Fig. 8), the proton auroral intensity shows some wave-like fluctuation ever since the growth phase, and its fluctuation level during the TSSO appears to be no larger than that during the growth phase. Note that in this 2008-03-05 event growth phase wave activities were indeed inferred from both the arc ewogram and in situ THEMIS data by Uritsky et al. (2009). This event was also examined in detail by Yue et al. (2015), who found that its growth phase CPS configuration is unstable to a ballooning mode. The above conclusions remain largely unchanged for the total 


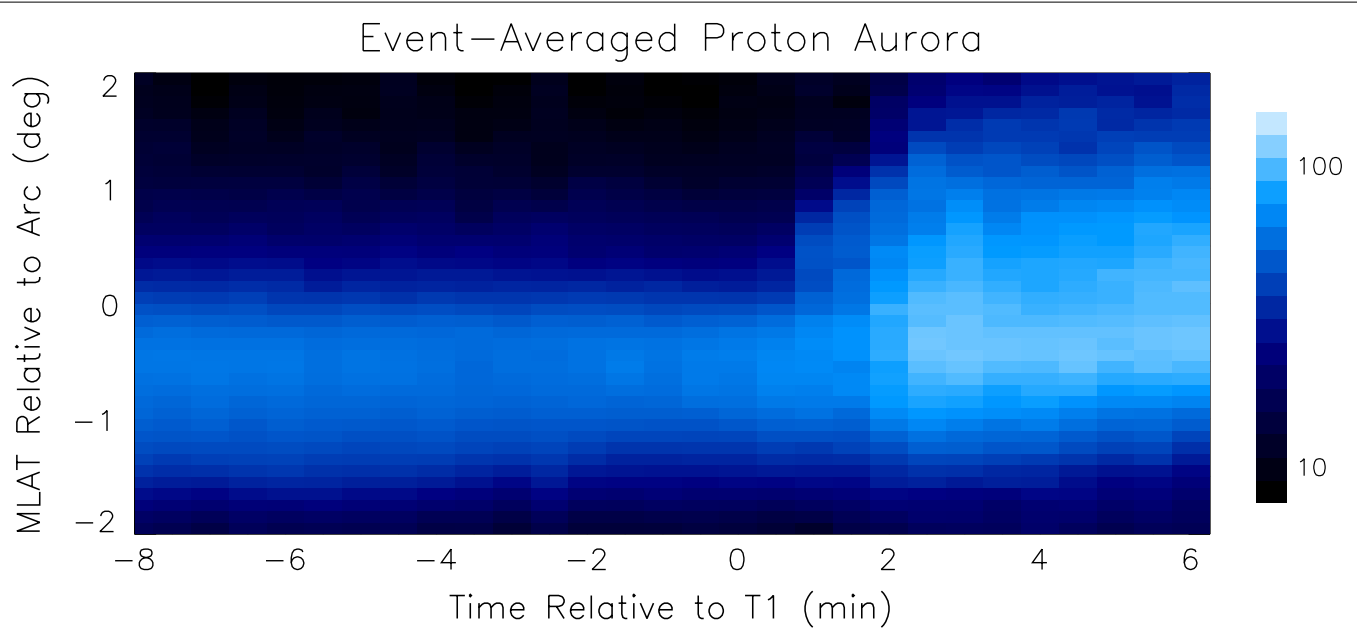

Fig. 9 Mean proton auroral profile versus relative time and MLAT. Proton auroral profiles averaged over our investigated events. $x$-axis denotes the time relative to $T 1$, while $Y$-axis denotes the MLAT relative to the center of arc

proton auroral intensity (Fig. 8e): the variations of the total proton auroral intensity are also mostly within $10 \%$ of its late-growth-phase level.

At last, we present in Fig. 9 the mean proton auroral profile versus time and MLAT, averaged over our events. The vertical axis denotes the MLAT relative to the center latitude of the arc in each event. In all of our investigated events, the arc is consistently located at the poleward shoulder of the main proton aurora band, a geometry clearly reflected in Fig. 9. The horizontal axis denotes the time relative to $T 1$, the start epoch of the poleward auroral expansion. Though we do not mark T0 in this plot format, it is clear that there is no notable variation of proton auroras in many minutes before $T 1$, throughout the late growth phase and the TSSO. Clues of substantial intensifications and poleward expansions of proton auroras are seen after $T 1$.

To summarize, we have reached the following conclusions on the proton auroral variations during the TSSO. The proton auroras during the TSSO can be either above or below their mean late growth phase values, but the relative variation is mostly within $\sim 10 \%$. Since such a variation level is also common during the late growth phase, we do not see much evidence that the TSSO activity adds special and appreciable contributions to the proton auroral variation. Substantial intensifications of proton auroras occur after the auroral poleward expansion.

\section{Discussion}

We have investigated the variations of electron auroral arc and proton auroras during the late growth phase and TSSO. Besides corroborating the previous notion that the preexisting and onset arc is usually situated at the poleward "shoulder" of the main proton auroral band (e.g., Lui and Burrows 1978; Samson et al. 1992; Donovan et al. 2012), the core new result in this study is that, during the TSSO when the electron auroral arc gradually enhances with intensity increasing by several times or even an order of magnitude, the proton auroral variations are much smaller or none during the TSSO. In passing, we also notice a poleward-propagating trace of emissions detached from the main proton auroral band after the expansion phase onset. In the following, we shall discuss a few possible explanations to the observations, and the implication of our results to the understanding of substorm onset mechanisms.

First of all, we shall clarify an important note regarding the spatial spreading nature of proton auroral emission and our technique. As we have mentioned in the "Introduction" section, the proton aurora undergoes nontrivial spatial broadening when the incident protons re-ionize/re-neutralize in the atmosphere. One thus may question our approach to study the proton aurora variation in the same latitudinal band as the electron arc. The spatial broadening of proton precipitation was first addressed and simulated via a Monte Carlo method by Davidson (1965). A more comprehensive and quantitative study in this regard, with improved profiles and chemical coefficients of the atmospheric model, was performed by Fang et al. (2004). Their study specifically and quantitatively discussed the spread of narrow proton arcs (see their Section 3.2 and Figure 12); some of our following arguments are based upon Fang et al. (2004)'s results. We shall remind the reader of two important aspects of the spatial spreading of proton auroras: (1) Such a spatial broadening is centered 
at, and the proton auroral intensity peaks around, the field-aligned footprint of the incident ion precipitation structure. That is the reason why, despite the spatial spreading, the proton auroras could still be used to pin down fairly localized structures such as the dipolarization fronts in the tail (Ge et al. 2012). The poleward-progressing trace of proton auroras during early expansion phase as we have noticed in our events has spatial scales distinctly smaller than $1^{\circ}$. (2) The width of the spatial broadening is not sensitive to the total precipitation flux or the exact energy of the incident protons, within the typical energy range of CPS ions. As can be seen from Figure 12 in Fang et al. (2004), while the spatial spreading effect indeed widens the proton/ hydrogen precipitating structure and reduces the peak flux intensity, the flux distribution still peaks at, and is largely concentrated around, the original arc. Had the ion precipitation flux truly enhanced considerably at the same flux tubes as the electron auroral arc during the TSSO, it should have left imprints in the proton auroral intensity sampled in the arc band, though the flux level would be somehow attenuated by the spatial spreading.

We shall perform a rough estimate on the degree of attenuation for an ion precipitation structure with width similar to the onset electron arc. In the simulation examples shown in Fang et al. (2004), the lowest halfwidth of the proton arc is $30 \mathrm{~km}$, in which the spreading causes the peak flux intensity at the arc center to decrease to $\sim 48 \%$ of the incident flux on top of the ionosphere. In our events the mean arc width is $\sim 0.33^{\circ}$ or $\sim 18.5 \mathrm{~km}$ in terms of halfwidth. We make a rough estimate by extrapolating Fang et al's given examples and infer that, for an arc halfwidth of $18 \mathrm{~km}$ the incident proton flux might be reduced to $\sim 36 \%$. In other words, the proton flux on top of the ionosphere is expected to be roughly 3 times as large as that after the spatial spreading. Assuming that the proton auroral intensity is proportional to the proton/hydrogen flux attenuated by the spatial spreading, since our observation indicates that the proton aurora averaged over the arc band is mostly within $\sim 10 \%$ of its mean late-growth-phase value, the variation of the arcrelated ion precipitation flux from the CPS (before the spatial spreading) is likely within $\sim 30 \%$ of its mean lategrowth-phase value, according to the above considerations. In comparison, the ion precipitation flux during a substorm dipolarization typically increases by several times (Gilson et al. 2012). It is key to note that, the spatial spreading effect of proton auroras applies to both the growth phase and the TSSO. Since we have noticed that the proton auroral variations are comparable in magnitude during the late growth phase and during the TSSO, our inference that the TSSO appears not to add much contribution to the arc-related ion precipitation flux still holds. To summarize, while it is true that the actual variation level of the ion precipitation flux in the CPS might be somehow higher than that reflected in proton auroras when the spatial spreading effect is considered, our main conclusions are not qualitatively altered.

Some may think that the invariance of proton auroras during the TSSO might be explained by the different propagation delay of electron precipitation and proton precipitation from the CPS to the ionosphere. It is certainly true that the thermal speed of CPS electrons is much faster than that of the ions, but this argument only applies to diffuse auroras. The proton aurora essentially belongs to the category of the diffuse aurora, namely that its precipitation is dominated by the loss cone flux from the CPS, without being much intervened by the auroral acceleration process. The substorm arc on the other hand, is well recognized as belonging to the "discrete aurora" category (e.g., Jiang et al. 2012). For a discrete aurora arc, the auroral acceleration and in turn the arc brightening is powered by Alfven waves and their carrying field-aligned currents (FAC), presumably originating from the magnetosphere (Wygant et al. 2000; Duan et al. 2016). In this regard, the M-I propagation delay from the magnetospheric "root" of the arc to the ionosphere is subject to the Alfven wave velocity $v_{\mathrm{A}}$,

$$
T_{\mathrm{A}}=\int \frac{\mathrm{d} s}{v_{\mathrm{A}}}=\int \frac{\sqrt{\mu_{0} \sum n_{i} m_{i}}}{B} \mathrm{~d} s .
$$

For the ion mass densities, we consider both the hot plasma of CPS origin and cold plasma of ionospheric origin. We resort to Yue et al. $(2013,2015)$ model to obtain the magnetospheric hot plasma density (assumed to be dominated by protons) and the magnetic field configuration, and assume the hot plasma density to be constant along the field line. In Yue et al. models, their authors collected extensive datasets of THEMIS/GEOTAIL data in the equator magnetosphere, and grouped them according to the solar wind dynamic pressure and the Kp index. They then used the observed equatorial plasma pressure as an input to the 3D force-balanced magnetic field solver to obtain the 3D magnetic field configuration. B-fields at $<4 \mathrm{R}_{\mathrm{E}}$ radial distance are considered as dipolar. For the ionospheric plasma, we assume the oxygen ion density $n_{\mathrm{O}}$ and the proton density $n_{\mathrm{P}}$ vary with altitude $z$ as (Shi et al. 2013):

$$
\begin{aligned}
& n_{\mathrm{O}}=2.5 \times 10^{5} \mathrm{~cm}^{-3} \cdot\left(\frac{z}{H}\right) \cdot e^{-z / H}, \\
& n_{\mathrm{P}}=100 \mathrm{~cm}^{-3} \cdot\left(\frac{R_{E}}{R_{E}+z}\right)^{8},
\end{aligned}
$$


where $H=400 \mathrm{~km}$ is the scale height of $\mathrm{O}^{+}$. From the above models we evaluate that, for an equatorial radial distance $L=10, T_{\mathrm{A}}$ typically ranges between $\sim 55$ and $85 \mathrm{~s}$ under various solar wind and $\mathrm{Kp}$ conditions in $22-24 \mathrm{~h}$ MLT sectors, while for $\sim 10 \mathrm{keV}$ protons at the same radial distance, their precipitation delay is about $\sim 50 \mathrm{~s}$. The likely existence of kinetic modification to Alfven waves (e.g., Lysak and Lotko 1996; Duan et al. 2016) may somehow increase the Alfvenic speed and thus decrease the propagation delay. However, considering the general range of $k_{y}$ as inferred from auroral beading observations (e.g., Liang et al. 2008; Nishimura et al. 2016) and typical ion acoustic gyroradius and thickness of the near-Earth CPS, the kinetic modification to Alfven transit delay is unlikely to reach a factor of 2 . Notwithstanding some uncertainty, one may semi-quantitatively draw from the above evaluation that the precipitation delay of energetic protons is roughly comparable to, if not slightly smaller than, the Alfvenic transit lag from the equatorial CPS to the ionosphere. Their propagation time difference is presumably within a couple of tens of seconds. Note that as our event criterion we postulate that the TSSO interval must be longer than $1 \mathrm{~min}$-and as a matter of fact the mean $T 1-T 0$ of our investigated events is $\sim 107 \pm 40 \mathrm{~s}$. Therefore, it seems impossible that the invariance of proton auroras during the TSSO could be attributed to different propagation delays of electron auroras and proton auroras from the equatorial magnetosphere to the ionosphere.

One might raise another possibility that, the electron auroral beading and brightening during the TSSO is purely an ionospheric process, and does not necessarily correspond to a driver activity in the equatorial magnetosphere. While this hypothesis occasionally existed in the literature (e.g., Sakaguchi et al. 2009), and we may not entirely exclude this possibility within our current knowledge of TSSO, it is fair to say that such a hypothesis does not have a definite observational support so far. To say the least, the results in Motoba et al. (2012) on the conjugacy between the shape and motion of auroral beads in the northern and southern hemispheres clearly favor an equatorial magnetospheric origin of the auroral beads. So far to the authors' knowledge, the view that TSSO has a magnetospheric driver prevails among substorm researchers. Our following discussions will be based upon such a view, even though we admit that the ionospheric role in TSSO is not well known so far.

The observational facts that, (a) the electron auroral arc does not show significant poleward expansion and (b) the proton aurora does not show noticeable variation, during the TSSO, strongly suggest that large-scale ion energization and magnetic dipolarization do not take place in the near-Earth CPS at that time. On the other hand, dipolarization fronts are known to be capable of producing sensible proton auroral features (Ge et al. 2012; Zhou et al. 2012). Since our observations (see event examples and Fig. 9) do not reveal noticeable proton aurora structures above the main proton auroral band shortly before and during the TSSO, the general co-existence of dipolarization fronts at NTR during the TSSO seems not to be supported either. A caveat must be given here. FESO and MSP scan only one meridian, while the fast flow channel and its attached dipolarization fronts are known to be limited in longitudinal extent (e.g., Liu et al. 2013). Also, as our event criterion, we limit our proton auroral measurements to be within the onset sector, yet the flow channel preceding the substorm onset does not necessarily penetrate into the NTR in the same longitudinal sector as the onset one (e.g., Nishimura et al. 2010). We witness in a few of our events that an auroral streamer activity extending to the arc indeed existed and shortly preceded the TSSO, but their contact longitude with the arc was away from the onset sector and the FESO or MSP meridian. Despite some controversy, many substorm researchers (e.g., Liu et al. 2012) conceive that substorm onsets can be either spontaneous or triggered by external disturbances such as fast earthward flows. The two types of onsets likely co-exist in our event pool. However, spontaneous or externally triggered, we do not recognize that they show fundamental difference in TSSO features or proton auroral variations, so that our research objective in this study is not affected.

A number of plasma instabilities have been dubbed as the potential mechanisms of TSSO by substorm researchers (e.g., Liu et al. 2012; Chang and Cheng 2015; Kalmoni et al. 2015; Nishimura et al. 2016; Lui 2016). It is far beyond the scope of the current paper to analyze and explore the actual instabilities at play during the TSSO, which is still an unclear and controversial issue to date. Instead, we shall present some general and conceptual arguments about the TSSO instabilities in order to qualitatively explain our observations. The TSSO presumably signifies an early stage of the instability growth; the perturbation magnitude of the instability is still limited and thus does not result in a dramatic change of the overall magnetospheric reconfiguration in the near-Earth CPS. Those instabilities are by nature wave processes, notably with finite $k_{y}$. For example, a ballooning mode perturbation typically consists of alternate segments of more-stretched and more-dipolarized regions, along the azimuthal direction (see, e.g., Figure 4 in Saito et al. 2008). The instability may inherently possess a real frequency, or even if it does not have one in the plasma rest frame (e.g., an ideal MHD ballooning mode), the Doppler effect led by the ion drifts would still cause the ion fluxes to fluctuate at a fixed observation point. In situ ion fluxes 
are expected to be modulated by these waves, either increasing or decreasing. Thus, it is fully understandable that the observed proton auroral intensity can be either higher or lower than the mean late-growth-phase level, contingent upon which wave segment/cycle the MSP meridian maps to when the scan intersects the arc. A similar level of proton auroral variation is seen during the late growth phase, hinting that the TSSO instability might already be present in the late growth phase (e.g., Saito et al. 2008; Liang et al. 2009). On the other hand, while corresponding oscillations of FACs would also exist with waves, and are indeed partially evidenced from the fluctuations of the sampled electron auroral intensities during the TSSO as can be seen in our event examples, the electron auroras would on overall grow with the upward FAC, since the effects of upward FACs and downward FACs on electron auroras are asymmetric. The possible existence of filamentary FAC structures in auroral beads was indeed inferred from flow shear observations by Hosokawa et al. (2013).

There are two potential processes that may act to suppress the variation of ion precipitation flux. First, it is widely conceived that the instability mode underlying TSSO likely involves some ion kinetic effects (e.g., Liang et al. 2008; Liu et al. 2012; Nishimura et al. 2016; Lui 2016). This is based upon the observation that, the azimuthal wavelength inferred from auroral beading structures, when mapped to equatorial magnetosphere, is usually found to be comparable to the gyroradius of energetic protons in the CPS. Under such a circumstance, the energetic ions are demagnetized; they are able to mix across the wave segments and thereby smooth their flux variations. A rough analysis is given here based upon the theory of a modified ballooning mode by Liu et al. (2012). The Ampere's Law yields $j_{/ /} \propto k_{y} \delta B_{n}$. The subscripts '//, ' $y$ ', ' $n$ ' denote the ambient magnetic field-aligned direction, the azimuthal direction, and the direction normal to the ambient magnetic field while lying in the meridional plane, respectively. On the other hand, as one can deduce from equations A18-A20 in Liu et al. (2012), in the limit $k_{y} \rightarrow \infty$ (full ion kinetic regime), the ion pressure perturbation $\delta p \propto \delta B_{n}$. Thus, the ratio $j_{/ /} / \delta p$ would increase toward large $k_{y}$, which is reflected in Figure 6 in Liu et al. (2012). At short azimuthal wavelengths, the ratio $j / / \delta p$ is high. The FAC can grow to a substantial magnitude, yet the perturbation of the ion pressure (deemed as a proxy as the omnidirectional flux) may remain limited due to the ion kinetic effect.

Secondly, the ion precipitation flux is also contingent upon the pitch-angle scattering rate, which is usually dominated by stochastic scattering due to curved field lines in the CPS (e.g., Sergeev et al. 1983; Donovan et al. 2003). In a more-dipolarized wave segment, the trapped ions might be energized so that the omnidirectional flux would increase. However, the field linecurvature decreases in this region, elevating the critical energy threshold so that fewer ions are scattered into the loss cone. Vice versa, in a more-stretched segment, the omnidirectional flux decreases, yet the scattering rate enhances. Such a competing effect between the omnidirectional flux and the scattering efficiency related to the change of magnetic field topology, was discussed and quantitatively investigated in Gilson et al. (2012). However, in the context of our research interest, since the arc is always located around the poleward edge of the main proton auroral band where the strong scattering condition is supposed to be met for most of the CPS thermal and energetic ions (e.g., Jiang et al. 2012), the change of the critical energy of pitch-angle scattering, due to a moderate change of the magnetic field topology, would at most play a minor role in the proton auroral variation.

One other factor at play is the parallel electric field in the auroral acceleration region associated with the arc. As the TSSO proceeds and upward FACs intensify, if a quasi-static upward E-field enhances accordingly in the auroral acceleration region, one would expect that precipitating protons passing through it would be somehow decelerated. Indeed, we have seen in some of our events (e.g., Event 1 in "Observations" section) that, the proton auroral intensity sampled in the onset arc band appears to show a small yet systematic decrease during the TSSO. Zou et al. (2010) noticed a reduction of ion differential fluxes around and below the peak energy of the electron inverted-V structure when REIMEI satellite passed over the onset arc, though the passage did not occur exactly during the TSSO but shortly after. However, we note that a systematic decrease of proton auroras in the arc band during the TSSO is not prevailing in our event pool: it is found in 4 out of 10 events (two low-elevation-angle cases are not considered). For all other vents, proton auroral intensities either slightly increase or oscillate during the TSSO. As shown in Fig. 8d, the data points are roughly evenly distributed in terms of positive or negative variations. We thus infer that, while the upward E-field in the auroral acceleration region might play a role in weakening the proton precipitation fluxes, its effect is far from overwhelming. We speculate that, in many cases the parallel electric potential might be distinctly smaller than the mean energy of precipitating CPS protons (which can be hinted from the observations in Zou et al. 2010), so that the decrease of total proton precipitation fluxes is limited. Nevertheless, it is possible that the arcassociated upward electric field might act competitively against a moderate increase of ion precipitation fluxes from the CPS during the TSSO, and partly account for the reduced variation level of proton auroras. 
At the end, we shall raise a caveat of the current study. Since the research purpose of this work is to investigate the proton auroral features during the TSSO, in our event survey and selection we only choose substorm events with clear signatures of TSSO and relatively unambiguous determination of $T 0$ and $T 1$. While it is fair to say, according to our own experiences and the existing literature (e.g., Kalmoni et al. 2017), substorms with distinct TSSO signatures are common, we do not claim them to be exclusive. We indeed occasionally noticed substorm events without clearly identifiable TSSO signatures; those events and their associated proton auroras are not considered in the current study. In our view, in terms of substorm onset mechanisms, we are less concerned about the difference between the spontaneous and externally triggered substorms - as long as they both have distinct TSSO features, but are more concerned about the difference between substorms with TSSO and those without TSSO. This is obviously another research topic left for future studies.

\section{Conclusion}

Optical auroral measurements repeatedly reveal that there is often a transitional stage between a quiescent preexisting arc and the significant auroral expansion in a substorm onset. The TSSO is characterized by a gradual intensification and in many cases the emergence of auroral beads, along the preexisting arc. However, the abovedepicted auroral dynamics are pertinent exclusively to electron auroras which are dominant in optical luminosity, while the variation of proton auroras during the TSSO is much less known. In this study, we use proton auroral measurements from the MSP and FESO instruments when they are within the initial onset sector of electron auroras observed by THEMIS/Rainbow ASIs, to study the proton auroral variation during the late growth phase and the TSSO. Our major results include: (1) we confirm the previous notion that the onset electron auroral arc is usually located at the poleward "shoulder" of the main proton auroral band. (2) While the electron auroral arc features nontrivial intensifications during the TSSO, the proton auroral intensity at the same latitudinal band as the auroral arc does not show appreciable variations. The proton aurora intensity during the TSSO is mostly within $\sim 10 \%$ of, either above or below, its mean lategrowth-phase value. Similar variation level is also seen in the late growth phase. Substantial intensifications of proton auroras occur after the start of the expansion phase of electron auroras.

The above observations of proton auroras during the TSSO impose implications and constraints on the possible mechanisms of substorm onset. Even when the spatial spreading of proton auroras is considered, our results still suggest that the relative change of ion precipitation fluxes throughout the late growth phase and the TSSO would be typically within $\sim 30 \%$. This invalidates the presence of strong ion energization and/or large-scale magnetic dipolarization in the near-Earth CPS during the TSSO. Instead, we suggest that underlying mechanism of the TSSO might be certain kind of $k_{y}$-dominated instability wave mode at its early stage. While the upward FACs contributing to the electron auroras grow substantially with the instability, the ion precipitation flux leading to proton auroras may have reduced fluctuation level, due to a combination of, (a) the ion demagnetization effect since the instability wavelength is comparable to the ion gyroradius, (b) the variation of pitch-angle scattering rate due to the change of the magnetic field topology, and (c) the upward electric field developed in the auroral acceleration region. The above hunch is to be tested in the context of relevant TSSO instabilities with realistic magnetospheric configuration in the future. Substorm model developers may consider simulating ion precipitation flux output with their models, to quantitatively compare with the proton auroral features reported in this study.

\section{Abbreviations}

THEMIS: Time History of Events and Macroscale Interactions during Substorms; ASI: all-sky imager; FoV: field-of-view; TSSO: transition stage of substorm onset; MSP: meridian scanning photometer; FESO: four-eight-six-one; CPS: central plasma sheet; NTR: nightside transition region; AACGM: altitude-adjusted corrected geomagnetic; MLAT: magnetic latitude; MLON: magnetic longitude.

\section{Authors' contributions}

$J$ : First-author who mainly conduct this study. ED: Supervising this study. PI of several optical instruments used in this study. DG: Responsible for the calibration of MSP data. ES: Managing the auroral data and the Auroral Imaging Group. MC: FESO is installed at the Athabasca University and managed by M. Connors. All authors read and approved the final manuscript.

\section{Authors' information}

Dr. J. Liang is a senior Research Scientist at the University of Calgary. His main research interest is on auroral phenomena and their associated dynamics in the Earth's magnetosphere. Prof. E. Donovan is an expert on the scientific and technical aspects of optical auroral observations, including proton auroras. All other co-authors are also expert on auroral studies.

\section{Author details \\ ${ }^{1}$ Department of Physics and Astronomy, University of Calgary, Calgary, Canada. ${ }^{2}$ Athabasca University Observatories, Athabasca, Canada.}

\section{Acknowledgements}

The authors acknowledge the excellent work of the Auroral Imaging Group of University of Calgary on the deployment and data management of THEMIS, Rainbow, MSP, and FESO projects. We thank the useful discussions with Dr. P. Zhu.

\section{Competing interests}

The authors declare that they have no competing interests.

\section{Availability of data and materials}

THEMIS all-sky-imager (ASI) data are publicly downloadable from the THEMIS website http://themis.ssl.berkeley.edu/data/themis/thg. MSP, FESO and Rainbow ASI are maintained by the Auroral Imaging Group at the University of 
Calgary, and the raw data can be found on http://data.phys.ucalgary.ca. MSP data are still undergoing calibration process; the data used in this study represent the most recent calibration work done by Dr. D. M. Gillies (co-author) at the University of Calgary. All data can also be requested upon contacting Prof. Eric Donovan (edonovan@ucalgary.ca).

\section{Consent for publication}

Not applicable.

Ethics approval and consent to participate

Not applicable.

\section{Funding}

The THEMIS mission is supported by NASA. Funding for the THEMIS ASI operation is provided by the Canadian Space Agency (CSA). Rainbow, FESO and MSP are all undertaken with the financial support of CSA. The authors would like to thank the Canada Foundation for Innovation (CFI) for providing the funding for the development and construction of the FESO instrument through Athabasca University.

\section{Publisher's Note}

Springer Nature remains neutral with regard to jurisdictional claims in published maps and institutional affiliations.

\section{Received: 21 March 2018 Accepted: 1 August 2018}

Published online: 06 August 2018

\section{References}

Akasofu SI (1964) The development of the auroral substorm. Planet Space Sci 12:273-282. https://doi.org/10.1016/0032-0633(64)90151-5

Chang TF, Cheng CZ (2015) Relationship between wave-like auroral arcs and Pi2 disturbances in plasma sheet prior to substorm onset. Earth Planets Space 67:168. https://doi.org/10.1186/s40623-015-0334-8

Davidson GT (1965) Expected spatial distribution of low-energy protons precipitated in the auroral zones. J Geophys Res 70(5):1061-1068. https:// doi.org/10.1029/JZ070i005p01061

Donovan EF, Jackel BJ, Voronkov I, Sotirelis T, Creutzberg F, Nicholson NA (2003) Ground-based optical determination of the b2i boundary: a basis for an optical MT-index. J Geophys Res 108:1115. https://doi.org/10.1029/2001 J A009198 (A3)

Donovan EF, Mende SB, Jackel BJ, Meurant M, Voronkov I, Frey HU, Angelopoulos V, Connors M (2006) The azimuthal evolution of the substorm expansive phase onset aurora. In: Syrjasuo M, Donovan EF (eds) Proceedings of international conference on substorms-8. University of Calgary, Calgary, pp 55-60

Donovan EF, Spanswick E, Liang J, Grant J, Jackel BJ, Greffen M (2012) Magnetospheric dynamics and the proton aurora. Auror Phenomenol Magnetos Process Earth Other Planets 197:365-378

Duan SP, Dai L, Wang C, Liang J, Lui ATY, Chen L, He ZH, Zhang YC, Angelopoulos $V$ (2016) Evidence of kinetic Alfvén eigenmode in the near-Earth magnetotail during substorm expansion phase. J Geophys Res Space Phys 121:4316-4330. https://doi.org/10.1002/2016JA022431

Fang X, Liemohn MW, Kozyra JU, Solomon SC (2004) Quantification of the spreading effect of auroral proton precipitation. J Geophys Res 109:A04309. https://doi.org/10.1029/2003JA010119

Galand M, Lilensten J, Kofman W, Sidge RB (1997) Proton transport model in the ionosphere: 1. Multistream approach of the transport equations. J Geophys Res 102:22261-22272. https://doi.org/10.1029/97JA01903

Ge YS, Zhou XZ, Liang J, Raeder J, Gilson ML, Donovan E, Angelopoulos V, Runov A (2012) Dipolarization fronts and associated auroral activities: 1. Conjugate observations and perspectives from global MHD simulations. J Geophys Res 117:A10226. https://doi.org/10.1029/2012JA017676

Gilson ML, Raeder J, Donovan YS, Ge Kepko L (2012) Global simulation of proton precipitation due to field line curvature during substorms. J Geophys Res 117:A05216. https://doi.org/10.1029/2012JA017562

Hosokawa K, Milan SE, Lester M, Kadokura A, Sato N, Bjornsson G (2013) Large flow shears around auroral beads at substorm onset. Geophys Res Lett 40:4987-4991. https://doi.org/10.1002/grl.50958
Jackel BJ, Creutzberg F, Donovan EF, Cogger LL (2003) Triangulation of auroral red-line emission heights. In: Proceedings of the atoms. Studies by Optical Methods, pp 1-4

Jackel BJ et al (2014) Auroral spectral estimation with wide-band color mosaic CCDs. Geosci Instrum Methods Data Syst 3:71-94

Jiang F et al (2012) In-situ observations of the "preexisting auroral arc" by THEMIS All Sky Imagers and the FAST spacecraft. J Geophys Res 117:A05211. https://doi.org/10.1029/2011JA017128

Kalmoni NME, Rae IJ, Watt CEJ, Murphy KR, Forsyth C, Owen CJ (2015) Statistical characterization of the growth and spatial scales of the sub storm onset arc. J Geophys Res Space Phys 120:8503-8516. https://doi. org/10.1002/2015JA021470

Kalmoni NME, Rae IJ, Murphy KR, Forsyth C, Watt CEJ, Owen CJ (2017) Statistical azimuthal structuring of the substorm onset arc: implications for the onset mechanism. Geophys Res Lett 44:2078-2087. https://doi. org/10.1002/2016GL071826

Liang J, Donovan EF, Liu WW, Jackel B, Mende SB, Frey HU, Angelopoulos V, Connors M (2008) Intensification of preexisting auroral arc at substorm expansion phase onset: wave-like disruption during the first tens of seconds. Geophys Res Lett 35:L17S19. https://doi.org/10.1029/2008G L033666

Liang J, Liu WW, Donovan EF (2009) lon temperature drop and quasielectrostatic electric field at the current sheet boundary minutes prior to the local current disruption. J Geophys Res 114:A10215. https://doi. org/10.1029/2009JA014357

Liang J, Donovan EF, Spanswick E, Angelopoulos V (2013) Multiprobe estimation of field line curvature radius in the equatorial magnetosphere and the use of proton precipitations in magnetosphere-ionosphere mapping. J Geophys Res Space Physics 118:4924-4945. https://doi. org/10.1002/jgra.50454

Liang J, Zhu P, Donovan EF, Saito M (2016) From the end of substorm growth phase till the first 1-2 minutes of onset: evidence of a transitional stage in optical auroral and in situ observations, SM52A-04. Paper presented at the AGU Fall Meeting, San Francisco, 12-16 December 2016

Liu WW, Donovan EF, Liang J, Voronkov I, Spanswick E, Jayachandran PT, Jackel B, Meurant M (2007) On the equatorward motion and fading of proton aurora during substorm growth phase. J Geophys Res 112:A10217. https //doi.org/10.1029/2007JA012495

Liu WW, Liang J, Donovan EF, Spanswick E (2012) If substorm onset triggers tail reconnection, what triggers substorm onset? J Geophys Res 117:A11220. https://doi.org/10.1029/2012JA018161

Liu J, Angelopoulos V, Zhou XZ, Runov A, Yao ZH (2013) On the role of pressure and flow perturbations around dipolarizing flux bundles. J Geophys Res 118:7104-7118. https://doi.org/10.1002/2013JA019256

Lui ATY (2016) Cross-field current instability for auroral bead formation in breakup arcs. Geophys Res Lett 43:6087-6095. https://doi. org/10.1002/2016GL069892

Lui ATY, Burrows JR (1978) On the location of auroral arcs near substorm onsets. J Geophys Res 83(A7):3342-3348

Lyons LR, Voronkov I, Donovan EF, Zesta E (2002) Relation of substorm breakup arc to other growth-phase auroral arcs. J Geophys Res 107(A11):1390. https://doi.org/10.1029/2002JA009317

Lysak RL, Lotko W (1996) On the kinetic dispersion relation for shear Alfven waves. J Geophys Res 101:5085-5094

Mende SB, Frey HU, Lampton M, Gérard JC, Hubert B, Fuselier SA, Spann J, Gladstone R, Burch JL (2001) Global observations of proton and electron auroras in a substorm. Geophys Res Lett 28:1139

Mende SB, Carlson CW, Frey HU, Peticolas LM, Østgaard N (2003) FAST and IMAGE-FUV observations of a substorm onset. J Geophys Res 108:1344. https://doi.org/10.1029/2002JA009787 (A9)

Mende SB, Harris SE, Frey HU, Angelopoulos V, Russell CT, Donovan E, Jackel B, Greffen M, Peticolas LM (2008) The THEMIS array of ground-based observatories for the study of auroral substorms. Space Sci Rev 141:357-387. https://doi.org/10.1007/s11214-008-9380-x

Motoba T, Hosokawa K, Kadokura A, Sato N (2012) Magnetic conjugacy of northern and southern auroral beads. Geophys Res Lett 39:L08108. https ://doi.org/10.1029/2012GL051599

Nishimura Y, Lyons LR, Zou S, Angelopoulos V, Mende SB (2010) Substorm triggering by new plasma intrusion: THEMIS all-sky imager observations. J Geophys Res 115:A07222. https://doi.org/10.1029/2009JA015166 
Nishimura Y et al (2016) Statistical properties of substorm auroral onset beads/rays. J Geophys Res Space Phys 121:8661-8676. https://doi. org/10.1002/2016JA022801

Ohtani S, Takahashi K, Zanetti LJ, Potemra TA, McEntire RW, lijima T (1992) Initial signatures of magnetic field and energetic particle fluxes at tail reconfiguration: explosive growth phase. J Geophys Res 97(A12):19311-19324. https://doi.org/10.1029/92JA01832

Pritchett PL, Coroniti FV (2013) Structure and consequences of the kinetic ballooning/interchange instability in the magnetotail. J Geophys Res Space Phys 118:146-159. https://doi.org/10.1029/2012JA018143

Rae IJ, Watt CEJ, Mann IR, Murphy KR, Samson JC, Kabin K, Angelopoulos $\checkmark$ (2010) Optical characterization of the growth and spatial structure of a substorm onset arc. J Geophys Res 115:A10222. https://doi. org/10.1029/2010JA015376

Saito MH, Miyashita Y, Fujimoto M, Shinohara I, Saito Y, Liou K, Mukai T (2008) Ballooning mode waves prior to substorm-associated dipolarizations: geotail observations. Geophys Res Lett 35:L07103. https://doi. org/10.1029/2008GL033269

Sakaguchi K, Shiokawa K, leda A, Nomura R, Nakajima A, Greffen M, Donovan E, Mann IR, Kim H, Lessard M (2009) Fine structures and dynamics in auroral initial brightening at substorm onsets. Ann Geophys 27:623-630

Samson JC, Lyons LR, Newell PT, Creutzberg F, Xu B (1992) Proton aurora and substorm intensifications. Geophys Res Lett 19:2167. https://doi. org/10.1029/92GL02184

Sergeev VA, Sazhina E, Tsyganenko N, Lundblad J, Soraas F (1983) Pitch-angle scattering of energetic protons in the magnetotail current sheet as the dominant source of their isotropic precipitation into the nightside ionosphere. Planet Space Sci 31:1147-1155

Shi R, Liu H, Yoshikawa A, Zhang B, Ni B (2013) Coupling of electrons and inertial Alfven waves in the topside ionosphere. J Geophys Res 118:29032910. https://doi.org/10.1002/jgra.50355
Spanswick E, Donovan EF, Kepko L, Angelopoulos V (2017) The magnetospheric source region of the bright proton aurora. Geophys Res Lett 44:10094-10099. https://doi.org/10.1002/2017GL074956

Uritsky VM, Liang J, Donovan EF, Spanswick E, Knudsen D, Liu WW, Bonnell J, Glassmeier KH (2009) Longitudinally propagating arc wave in the pre-onset optical aurora. Geophys Res Lett 36:L21103. https://doi. org/10.1029/2009GL040777

Voronkov I, Rankin R, Frycz P, TikhonchukVT, Samson JC (1997) Coupling of shear flow and pressure gradient instabilities. J Geophys Res 102:9639_ 9650. https://doi.org/10.1029/97JA00386

Wygant JR et al (2000) Polar spacecraft based comparisons of intense electric fields and Poynting flux near and within the plasma sheet tail lobe boundary to UVI images: an energy source for the aurora. J Geophys Res 105(18):675-18692. https://doi.org/10.1029/1999JA900500

Yue C, Wang CP, Zaharia SG, Xing X, Lyons L (2013) Empirical modeling of plasma sheet pressure and three-dimensional force-balanced magnetospheric magnetic field structure: 2. Modeling. J Geophys Res Space Phys 118:6166-6175. https://doi.org/10.1002/2013JA018943

Yue C, Wang CP, Nishimura Y, Murphy KR, Xing X, Lyons L, Henderson M, Angelopoulos V, Lui ATY, Nagai T (2015) Empirical modeling of 3-D force-balanced plasma and magnetic field structures during substorm growth phase. J Geophys Res Space Phys 120:6496-6513. https://doi. org/10.1002/2015JA021226

Zhou XZ, Ge YS, Angelopoulos V, Runov A, Liang J, Xing X, Raeder J, Zong QG (2012) Dipolarization fronts and associated auroral activities: 2. Acceleration of ions and their subsequent behavior. J Geophys Res 117:A10227. https://doi.org/10.1029/2012JA017677

Zou $S$ et al (2010) Identification of substorm onset location and preonset sequence using Reimei, THEMIS GBO, PFISR, and Geotail. J Geophys Res 115:A12309. https://doi.org/10.1029/2010JA015520

\section{Submit your manuscript to a SpringerOpen ${ }^{\odot}$ journal and benefit from:}

- Convenient online submission

- Rigorous peer review

- Open access: articles freely available online

- High visibility within the field

- Retaining the copyright to your article

Submit your next manuscript at springeropen.com 